\title{
Targeted disruption of GAK stagnates autophagic flux by disturbing lysosomal dynamics
}

\author{
MASAYA MIYAZAKI $^{1}$, MASAKI HIRAMOTO $^{1}$, NAOHARU TAKANO $^{1}$, HIROKO KOKUBA $^{2}$, JUN TAKEMURA $^{1}$, \\ MAYUMI TOKUHISA $^{1}$, HIROTSUGU HINO ${ }^{1}$, HIROMI KAZAMA ${ }^{1}$ and KEISUKE MIYAZAWA ${ }^{1}$ \\ ${ }^{1}$ Department of Biochemistry, ${ }^{2}$ Laboratory of Electron Microscopy, Tokyo Medical University, Tokyo 160-8402, Japan
}

Received April 27, 2021; Accepted August 5, 2021

DOI: $10.3892 / \mathrm{ijmm} .2021 .5028$

\begin{abstract}
The autophagy-lysosome system allows cells to adapt to environmental changes by regulating the degradation and recycling of cellular components, and to maintain homeostasis by removing aggregated proteins and defective organelles. Cyclin G-associated kinase (GAK) is involved in the regulation of clathrin-dependent endocytosis and cell cycle progression. In addition, a single nucleotide polymorphism at the GAK locus has been reported as a risk factor for Parkinson's disease. However, the roles of GAK in the autophagy-lysosome system are not completely understood, thus the present study aimed to clarify this. In the present study, under genetic disruption or chemical inhibition of GAK, analyzing autophagic flux and observing morphological changes of autophagosomes and autolysosomes revealed that GAK controlled lysosomal dynamics via actomyosin regulation, resulting in a steady progression of autophagy. GAK knockout (KO) in A549 cells impaired autophagosome-lysosome fusion and autophagic lysosome reformation, which resulted in the accumulation of enlarged autophagosomes and autolysosomes during prolonged starvation. The stagnation of autophagic flux accompanied by these phenomena was also observed with the addition of a GAK inhibitor. Furthermore, the addition of Rho-associated
\end{abstract}

Correspondence to: Dr Masaki Hiramoto, Department of Biochemistry, Tokyo Medical University, 6-1-1 Shinjuku, Shinjuku-ku, Tokyo 160-8402, Japan

E-mail: hiramoto@tokyo-med.ac.jp

Abbreviations: ALR, autophagic lysosome reformation; CTSB, cathepsin B; CTSD, cathepsin D; EGFR, epidermal growth factor receptor; GAK, cyclin G-associated kinase; Gln, glutamine; HBSS, Hanks' balanced salt solution; HCQ, hydroxychloroquine; $\mathrm{KO}$, knockout; Baf, Bafilomycin $\mathrm{A}_{1}$; LAMP, lysosomal associated membrane protein; LRRK2, leucine-rich repeat kinase 2; NSCLC, non-small cell lung cancer; OE, overexpression; PD, Parkinson's disease; ROCK, Rho-associated protein kinase; S6, ribosomal protein S6; S6K, ribosomal protein S6 kinase

Key words: cyclin G-associated kinase, autophagy, autophagosome-lysosome fusion, autophagic lysosome reformation, Rho-associated protein kinase, actomyosin protein kinase (ROCK) inhibitor or ROCK1 knockdown mitigated GAK KO-mediated effects. The results suggested a vital role of GAK in controlling lysosomal dynamics via maintaining lysosomal homeostasis during autophagy.

\section{Introduction}

Macroautophagy (hereafter referred to as autophagy) is an intracellular catabolic pathway essential for maintaining cellular homeostasis $(1,2)$. Autophagy is activated under nutrient-starved conditions to induce bulk turnover of cytoplasmic contents, including proteins and organelles, whereas basal autophagy occurs under nutrient-rich conditions and is important for the quality control of intracellular proteins and organelles $(3,4)$. Autophagy is initiated by the formation of isolation membranes (also known as phagophores), which expand to form double-membrane autophagosomes containing cytoplasmic cargo, and then subsequently fuse with lysosomes to form single-membrane degradative compartments, autolysosomes (5-7). The low internal $\mathrm{pH}$ and acidic enzymes, such as cathepsins (CTSs), degrade the autolysosomal content to generate simple molecules, including amino acids, which are then recycled back to the cytoplasm for reuse $(8,9)$. The rate at which this tightly regulated multistep dynamic process occurs inside the cells is referred to as autophagic flux. As autophagy is a fundamental control system that maintains the homeostasis of cells and organisms, disturbances in autophagy have been implicated in various human disorders, including neurodegenerative diseases and cancer $(10,11)$.

Lysosomes are membrane-enclosed cytoplasmic organelles that mediate the degradation of various biological macromolecules, including proteins, and the adaptation of cell metabolism to environmental cues (12). Lysosomes are not static organelles, but highly dynamic structures that move around the cytoplasm to change their size and shape or to undergo fusion or fission $(13,14)$. In autophagic flux, lysosomes fuse with autophagosomes to form autolysosomes and are reformed by fission from autolysosomes, a process called autophagic lysosome reformation (ALR) $(9,15)$. mTORC1, a key regulator of autophagy, localizes on lysosomes and senses cellular nutrients (16-18). When the nutrients are limited, mTORC1 is deactivated, which induces autophagy. Subsequently, the release of free amino acids from autolysosomes upon autophagy induction reactivates mTORC1, triggering ALR $(15,19)$. In 
addition, actomyosin dynamics also serve essential roles in each step of the autophagic process, including biogenesis of autophagosomes, autophagosome-lysosome fusion and $\operatorname{ALR}(20,21)$.

Cyclin G-associated kinase (GAK) is a ubiquitously expressed serine/threonine-protein kinase that primarily localizes to the perinuclear trans-Golgi and the plasma membrane regions $(22,23)$. GAK, which was initially identified as a direct partner of cyclin G (24), has been associated with a diverse range of biological processes, including the maintenance of centrosome maturation and cell cycle progression (25-28), clathrin-mediated endocytosis $(22,23,29-31)$, epidermal growth factor receptor (EGFR) signaling (32) and lysosomal enzyme sorting (33). In addition, GAK has been reported as a binding partner of leucine-rich repeat kinase 2 (LRRK2) (34), which has previously been reported to control autophagy in several systems (35-37). Regarding human disorders, GAK is overexpressed in osteosarcoma cells and tissues (38), and a single nucleotide polymorphism (SNP) rs1564282 in the intronic region of GAK is associated with susceptibility to Parkinson's disease (PD) (39-41).

The relationship between GAK and clathrin-mediated endocytosis has been extensively studied, but the relationship between GAK and the autophagy-lysosome system is not completely understood. To determine whether GAK serves an essential role in the autophagy-lysosome system, the present study performed targeted disruption of GAK in non-small cell lung cancer (NSCLC) A549 cells, analyzed the fluctuation of autophagic flux and examined the underlying molecular mechanism.

\section{Materials and methods}

Reagents. Bafilomycin $\mathrm{A}_{1}(\mathrm{Baf})$, puromycin, blasticidin $\mathrm{S}$ and Hanks' balanced salt solution (HBSS) were purchased from FUJIFILM Wako Pure Chemical Corporation. Rapamycin was obtained from LC Laboratories. Hydroxychloroquine (HCQ) was obtained from Cayman Chemical Company. The GAK inhibitor (GAKi; cat. no. 538770), Y-27632 (cat. no. 688000) and cycloheximide were purchased from Calbiochem (Merck $\mathrm{KGaA}$ ). DAPI was obtained from Sigma-Aldrich (Merck $\mathrm{KGaA}$ ). Protease inhibitor cocktail and phosphatase inhibitor cocktail were obtained from Nacalai Tesque, Inc. Baf and rapamycin were dissolved in DMSO and used at a concentration of $10 \mathrm{nM}$, and the same amount of DMSO was used for negative control. HCQ was dissolved in water and used at a concentration of $50 \mu \mathrm{M}$. GAKi was dissolved in DMSO and used at the indicated concentrations $(3,10$ or $30 \mu \mathrm{M})$, and the same amount of DMSO was used for negative control. Y-27632 was dissolved in water and used at a concentration of $10 \mu \mathrm{M}$. Cycloheximide was dissolved in DMSO and used at a concentration of $30 \mu \mathrm{M}$. Cells treated with Baf (8 or $24 \mathrm{~h})$, rapamycin ( $24 \mathrm{~h}), \mathrm{HCQ}$ (8 or $24 \mathrm{~h}$ ), GAKi (8 or $12 \mathrm{~h}$ ), Y-27632 $(8 \mathrm{~h})$ or cycloheximide $(3,9$ or $24 \mathrm{~h})$ at $37^{\circ} \mathrm{C}$ with $5 \% \mathrm{CO}_{2}$ for an indicated period of time.

Antibodies. The following primary antibodies were used in the present study: Anti-GAK (cat. no. M057-3; Medical \& Biological Laboratories Co., Ltd.), anti-phosphorylated (p)-mTOR (cat. no. 5536), anti-mTOR (cat. no. 2983), anti-p-ribosomal protein S6 kinase (S6K; cat. no. 9234), anti-S6K (cat. no. 2708), anti-p-S6 (cat. no. 4858), anti-S6 (cat.no.2217;), anti-p-AMPK (cat.no.2535), anti-AMPK (cat. no. 5832), anti-LC3B for immunocytochemistry (cat. no. 2775), anti-p62/sequestosome 1 (SQSTM1; cat. no. 7695), anti-CTSB (cat. no. 31718), and anti-CTSD (cat. no. 2284), anti-ROCK1 (cat. no. 4035; all from Cell Signaling Technology, Inc.), anti-lysosomal associated membrane protein (LAMP)1 (cat. no. sc-20011), anti-LAMP2 (cat. no. sc-18822), anti- $\beta$-actin (cat. no. sc-47778), anti-GAPDH (cat. no. sc-32233; all from Santa Cruz Biotechnology, Inc.), anti-LC3B for immunoblotting (cat. no. NB600-1384; Novus Biologicals, LLC), anti-FLAG (cat. no. F1804; Sigma-Aldrich; Merck KGaA) and anti-V5 (R960-25; Invitrogen; Thermo Fisher Scientific, Inc.). Horseradish peroxidase-conjugated secondary antibodies against mouse IgG (cat. no. 115-035-003) and rabbit IgG (cat. no. 711-035-152) were purchased from Jackson ImmunoResearch Laboratories, Inc. The Alexa Fluor 555-conjugated secondary antibody against mouse IgG (cat. no. A21424) and Alexa Fluor 488-conjugated secondary antibody against rabbit IgG (cat. no. A11034) were obtained from Invitrogen (Thermo Fisher Scientific, Inc.).

Cell culture. The human NSCLC cell lines (A549 and H596), human pancreatic cancer cell line (PANC-1) and human liver cancer cell line (Hep-G2) were purchased from American Type Culture Collection. Cells were cultured in RPMI-1640 (Sigma-Aldrich; Merck KGaA) supplemented with $10 \%$ heat-inactivated FBS (Gibco; Thermo Fisher Scientific, Inc.) at $37^{\circ} \mathrm{C}$ with $5 \% \mathrm{CO}_{2}$. Stable A549/GFP-LC3-mCherry-LC $3 \Delta \mathrm{G}$ cells were cultured under the same conditions as A549 cells with the addition of puromycin $(2 \mu \mathrm{g} / \mathrm{ml})$. RPMI medium without serum and glutamine (RPMI-Gln) was prepared by dissolving RPMI-1640 without glutamine and sodium bicarbonate (cat. no. 05918; Nissui Pharmaceutical Co., Ltd.) in water, followed by autoclaving and then adding sterilized sodium bicarbonate. 293T cells were cultured in DMEM (Sigma-Aldrich; Merck KGaA) supplemented with 10\% FBS at $37^{\circ} \mathrm{C}$ with $5 \% \mathrm{CO}_{2}$.

CRISPR/Cas 9 genome editing. Target sequences for CRISPR interference (42) were designed using CRISPR direct (http://crispr.dbcls.jp/) provided by the Database Center for Life Science. The target sequences for human GAK were GCAGTCGGCGCTCGACTTCT (exon 1; N-terminus) or GAGGCCCCCTTTCGTGCGACA (exon 5; kinase domain). Subsequently, two complementary oligonucleotides with BpiI restriction sites for guide RNAs (gRNAs) were synthesized at Eurofins Genomics and cloned into the pSpCas9(BB)-2A-Puro (PX459) vector (cat. no. 48139; Addgene, Inc.), deposited by the Feng Zhang Laboratory (43). A549 cells $\left(2 \times 10^{6}\right.$ cells/100 mm dish) were transfected with pX459-gRNA $(10 \mu \mathrm{g})$ using Lipofectamine ${ }^{\circledR} 2000$ (Invitrogen; Thermo Fisher Scientific, Inc.) according to the manufacturer's instructions. Following culture at $37^{\circ} \mathrm{C}$ with $5 \% \mathrm{CO}_{2}$ overnight, cells were treated with $2 \mu \mathrm{g} / \mathrm{ml}$ puromycin for 2 days. Surviving cells were diluted in growth medium (RPMI-1640 supplemented with $10 \%$ heat-inactivated FBS) to prepare a cell suspension $(5$ cells $/ \mathrm{ml})$. Then, $100 \mu 1$ cell suspension was added to each well of a 96-well plate. The expression of GAK in the 
expanded colonies was detected by immunoblotting, described in the immunoblotting section, using an anti-GAK antibody to select GAK-depleted colonies. The genome sequences of the edited locus in selected colonies were confirmed by Sanger DNA sequencing performed at Eurofins Genomics, which demonstrated that the expected mutation and frameshifting were present in each exon of GAK (Fig. S1). After cloning and expansion, A549/GAK-knockout (KO) cells were cultured under the same conditions as A549 cells and used for subsequent experiments.

Establishment of stable cell lines. The stable cell line was generated by transfecting A549/GAK-KO cells $\left(2 \times 10^{6}\right.$ cells $/ 100 \mathrm{~mm}$ dish $)$ with plasmid DNA (pMRX-IP-GFP-LC3-mCherry-LC3 $\Delta \mathrm{G} ; 10 \mu \mathrm{g}$ ) using Lipofectamine 2000 according to the manufacturer's instructions and cultured at $37^{\circ} \mathrm{C}$ with $5 \% \mathrm{CO}_{2}$ overnight. As previously described (44), the pMRX-IP-GFP-LC3-mCherry-LC3 $\Delta \mathrm{G}$ plasmid used in the present study was recombined with the pMRX-IP-GFP-LC3-RFP-LC3 $\Delta$ G plasmid, which was a kind gift from Dr N. Mizushima (University of Tokyo, Japan) (45). After selecting the transfected cells using puromycin $(1 \mu \mathrm{g} / \mathrm{ml})$ from the day after transfection, single clones of the cells were isolated and the expression of transfected genes was confirmed by immunoblotting. After cloning and expansion, A549/GAK-KO/GFP-LC3-mCherry-LC3 $\Delta$ G cells were cultured under the same conditions as A549 cells with the addition of $1 \mu \mathrm{g} / \mathrm{ml}$ puromycin. Since A549/GAK-KO cells are more sensitive to puromycin than A549 cells, puromycin was used at a concentration of $1 \mu \mathrm{g} / \mathrm{ml}$.

Transduction of lentiviral vectors. To construct the lentiviral expression vector, pLentiN-GAK, GAK cDNA was amplified by PCR. Total RNA was isolated from A549 cells using the NucleoSpin RNA kit (cat. no. U0955C; Takara Bio, Inc.) according to the manufacturer's protocol. cDNA was synthesized from the total RNA using the SuperScript III First-Strand Synthesis system (cat. no. 18080-051; Invitrogen; Thermo Fisher Scientific, Inc.) according to the manufacturer's protocol. cDNA for GAK was amplified using PrimeSTAR HS DNA Polymerase (cat. no. R010A; Takara Bio, Inc.) according to the manufacturer's protocol. The primers used for amplification were as follows: forward, 5'-CACCGG TACCCACCATGTCGCTGCTGCAGTCGGCGCTC-3' and reverse, 5'-AGCTGAATTCTCACTTGTCGTCGTCATCCT TGTAGTCGA AGAGGGGCCGGGAGCCCTG-3'. The thermocycling conditions were as follows: $98^{\circ} \mathrm{C}$ for $1 \mathrm{~min}$; followed by 30 cycles of $98^{\circ} \mathrm{C}$ for $10 \mathrm{sec}, 60^{\circ} \mathrm{C}$ for $5 \mathrm{sec}$ and $72^{\circ} \mathrm{C}$ for $4 \mathrm{~min}$; and $72^{\circ} \mathrm{C}$ for $5 \mathrm{~min}$. During PCR amplification, FLAG-tag was fused at the C-terminus of GAK. The amplified GAK cDNA was subcloned into the pcDNA6 mammalian expression vector (Invitrogen; Thermo Fisher Scientific, Inc.). The cloned sequences were verified by Sanger sequencing at Eurofins Genomics (Fig. S2). The DNA inserts encoding GAK were then subcloned into the pLentiN lentiviral expression vector, which was a kind gift from Dr Karl Munger (cat. no. 37444; Addgene, Inc.) using restriction enzymes, SpeI and EcoRI (46). To construct the lentiviral short hairpin RNA (shRNA) vectors, pLKO.1- Rho-associated protein kinase (ROCK)1, oligonucleotides for shRNAs targeting ROCK1 on appropriate sites and a non-targeting (NT) control oligonucleotide were synthesized (Table SI). The oligonucleotides were phosphorylated, annealed and inserted into the pLKO.1 puro lentiviral shRNA vector, which was a kind gift from Dr Bob Weinberg (cat. no. 8453; Addgene, Inc.) (47). The production and transduction of lentiviral particles were performed as previously described (48). Briefly, 293T cells (1x107 cells $/ 100 \mathrm{~mm}$ dish) were cotransfected with the constructed plasmid (pLentiN-GAK, pLentiN-empty, pLKO.1-ROCK1 or pLKO.1-NT; all $4 \mu \mathrm{g}$ ), pMD2.G (a gift from Dr Didier Trono; cat. no. 12259; Addgene, Inc.; $2 \mu \mathrm{g}$ ) and psPAX2 (a gift from Dr Didier Trono; cat. no. 12260; Addgene, Inc.; $2 \mu \mathrm{g}$ ) using PEI-MAX (cat. no. 24765-1, Polysciences, Inc.; $24 \mu \mathrm{g}$ ) and cultured at $37^{\circ} \mathrm{C}$ with $5 \% \mathrm{CO}_{2}$. At 2 days post-transfection, the cultured supernatant containing lentivirus was harvested and filtrated. The titer of lentiviral particles was not determined. A549 and A549/GAK-KO cells were plated ( $2 \times 10^{5}$ cells/well) in 6-well plate for $24 \mathrm{~h}$ before transduction and infected with the prepared lentivirus $(150 \mu \mathrm{l})$ at $37^{\circ} \mathrm{C}$ with $5 \% \mathrm{CO}_{2}$ overnight, and selected using blasticidin $\mathrm{S}(10 \mu \mathrm{g} / \mathrm{ml}$ for A549 cells; $5 \mu \mathrm{g} / \mathrm{ml}$ for A549/GAK-KO cells) or puromycin ( $2 \mu \mathrm{g} / \mathrm{ml}$ for A549 cells; $1 \mu \mathrm{g} / \mathrm{ml}$ for A549/GAK-KO cells) from the day after infection. In the present study, the following cell lines were established: A549/GAK-KO/GAK-rescued, A549/GAK-KO/sham-rescued, A549/GAK-overexpression (OE), A549/sham-OE, A 549/GAK-KO/shROCK1\#1, A549/GAK-KO/shROCK1\#2 and A549/GAK-KO/shNT cells. A549/GAK-KO/sham-rescued and A549/sham-OE cells were established using pLentiN-empty. The established cell lines were cultured under the same conditions as A549 cells, except for the supplementation of blasticidin S for GAK-rescued cells or puromycin for ROCK1-knockdown cells.

Immunoblotting. Total cellular proteins were extracted from A549 and A549/GAK-KO cells under the following conditions at $37^{\circ} \mathrm{C}$ with $5 \% \mathrm{CO}_{2}$ : i) Basal-fed condition (RPMI-1640 supplemented with $10 \%$ FBS); ii) starved condition using RPMI-GIn (2, 4, 6 or $8 \mathrm{~h})$; iii) basal-fed condition with $30 \mu \mathrm{M}$ cycloheximide (3, 9 or $24 \mathrm{~h})$; iv) starved condition using HBSS ( $2 \mathrm{~h})$; v) refed condition (starvation using HBSS or RPMI-Gln for $1 \mathrm{~h}$, followed by fed conditions for $1 \mathrm{~h}$ ) using lysis buffer containing $50 \mathrm{mM}$ Tris- $\mathrm{HCl}$ (pH 8.0), 150 mM NaCl, 1.0\% Nonidet P-40, $0.5 \%$ sodium deoxycholate, $0.1 \%$ SDS, and protease and phosphatase inhibitor cocktails. Each sample was sonicated on ice for 20 pulses $(0.5 \mathrm{sec}$ on/off) to solubilize the aggregated proteins using a Branson 450D Sonifier (Emerson Electric Co.). Protein concentrations were measured using the BCA Protein Assay kit (Thermo Fisher Scientific, Inc.) according to the manufacturer's instructions. Equal amounts $(10 \mu \mathrm{g})$ of proteins were resolved by SDS-PAGE (10\% gel or 5-20\% gradient gel) and transferred onto Immobilon-P PVDF membranes (Merck KGaA). Following blocking with $5 \%$ non-fat milk for $1 \mathrm{~h}$ at room temperature, the membranes were probed with primary antibodies at $4^{\circ} \mathrm{C}$ overnight. Primary antibodies used for immunoblotting were as follows: Anti-LC3B (1:2,000), anti-GAK (1:500), anti-LAMP1 (1:1,000), anti-LAMP2 (1:1,000), anti-p-mTOR $(1: 1,000)$, anti-mTOR $(1: 1,000)$, anti-p-AMPK $(1: 1,000)$, anti-AMPK $(1: 1,000)$, anti-p-S6K $(1: 1,000)$, anti-S6K $(1: 1,000)$, anti-p-S6 (1:1,000), anti-S6 (1:1,000), anti-CTSB $(1: 1,000)$, anti-CTSD $(1: 1,000)$, anti-SQSTM1 $(1: 1,000)$, anti-ROCK1 
(1:1,000), anti-FLAG $(1: 1,000)$, anti-V5 $(1: 5,000)$, anti-GAPDH $(1: 1,000)$, and anti- $\beta$-actin $(1: 1,000)$. These membranes were incubated with horseradish peroxidase-conjugated secondary antibodies (anti-mouse IgG or anti-rabbit IgG; both 1:2,500) for $1 \mathrm{~h}$ at room temperature. Immunoreactive proteins were detected using Immobilon Western HRP substrate detection reagents (Merck KGaA). Densitometry analysis was performed using a WSE-6300 Luminograph III molecular imager (ATTO Corporation) and CSAnalyzer4 software version 2.3.1 (ATTO Corporation).

Immunocytochemistry. A549, A549/GAK-KO and A549/GAK-rescued cells were seeded $\left(4 \times 10^{4}\right.$ cells/well) onto glass coverslips in a 24-well culture plate and incubated for $48 \mathrm{~h}$. After washing with PBS, cells were fixed with $100 \%$ methanol at $-30^{\circ} \mathrm{C}$ for $15 \mathrm{~min}$. After washing with TBST (0.05\% Tween-20), cells were blocked with $10 \%$ newborn calf serum (Gibco; Thermo Fisher Scientific, Inc.) in TBST at room temperature for $1 \mathrm{~h}$, followed by incubation with primary antibodies in TBST containing 1.5\% newborn calf serum and $0.1 \%$ BSA (Nacalai Tesque, Inc.) at $4^{\circ} \mathrm{C}$ overnight. Primary antibodies used for immunocytochemistry were follows: Anti-LC3B (1:100) and anti-LAMP2 (1:100). After washing with TBST, cells were incubated with Alexa Fluor 488-conjugated anti-rabbit IgG and/or Alexa Fluor 555-conjugated anti-mouse $\operatorname{IgG}$ (both 1:1,000) along with DAPI at $37^{\circ} \mathrm{C}$ for $1 \mathrm{~h}$. Cells were washed again with TBST then mounted in ProLong Diamond Antifade Mountant (Invitrogen; Thermo Fisher Scientific, Inc.). Stained cells were visualized using a Zeiss LSM700 confocal laser scanning fluorescence microscope (Zeiss $\mathrm{GmbH}$ ) equipped with PlanApochromat $63 \mathrm{x} / 1.4$ or 100x/1.4 oil DIC (Zeiss GmbH). All images were acquired and processed using ZEN 2012 software (version 8.1.0.484; Zeiss $\mathrm{GmbH})$. Object-based fluorescence intensity was measured using ImageJ software (version 1.50i; National Institutes of Health). The size of lysosomes was measured using ZEN 2012 software. The number of autophagosomes was automatically recognized based on size and intensity thresholds using the Spot function in Imaris x64 software (version 9.1.0; Oxford Instruments Bitplane) (49).

Assessment of autophagic flux using GFP-LC3$m$ Cheery-LC3 $\Delta G$ system. A549/GFP-LC3-mCherry-LC3 $\Delta \mathrm{G}$ and A549/GAK-KO/GFP-LC3-mCherry-LC3 $\Delta$ G cells were plated $\left(8 \times 10^{3}\right.$ cells/well $)$ in a 96 -well plate for $24 \mathrm{~h}$ before treatment. Fluorescence intensities derived from GFP-LC3 and mCherry-LC $3 \Delta \mathrm{G}$ were monitored during the $24 \mathrm{~h}$-culture at $37^{\circ} \mathrm{C}$ with $5 \% \mathrm{CO}_{2}$ using an IncuCyte $\mathrm{ZOOM}$ cell imaging system (Essen BioScience) under the following conditions: i) Basal-fed condition (RPMI-1640 supplemented with $10 \%$ FBS); ii) basal-fed condition with $10 \mathrm{nM} \mathrm{Baf}$; iii) basal-fed condition with $10 \mathrm{nM}$ rapamycin; iv) basal-fed condition with DMSO; v) starved condition using HBSS; vi) starved condition using RPMI-Gln; vii) starved condition using HBSS with GAKi $(3,10$ or $30 \mu \mathrm{M})$; and viii) starved condition using RPMI-Gln with GAKi $(3,10$ or $30 \mu \mathrm{M})$. Autophagic flux was presented as alterations in the relative intensities of GFP/mCherry calculated using Microsoft Excel version 16.51 (Microsoft Corporation) from the measured fluorescence intensities of GFP and mCherry.
LysoTracker/LysoSensor staining. A549, A549/GAK-KO and A549/GAK-rescued cells were seeded $\left(4 \times 10^{4}\right.$ cells/well) into glass-bottom cell culture dishes (Greiner Bio-One International $\mathrm{GmbH}$ ). After a 48-h culture, cells were incubated under basal-fed (RPMI-1640 supplemented with 10\% FBS) or starvation conditions (RPMI-Gln) for $8 \mathrm{~h}$ at $37^{\circ} \mathrm{C}$ with $5 \% \mathrm{CO}_{2}$ and then incubated for $1 \mathrm{~h}$ with $50 \mathrm{nM}$ LysoTracker Red DND-99 (cat. no. L7528; Invitrogen; Thermo Fisher Scientific, Inc.) or $1 \mu \mathrm{M}$ LysoSensor Green DND-189 (cat. no. L7535; Invitrogen; Thermo Fisher Scientific, Inc.) at $37^{\circ} \mathrm{C}$ with $5 \% \mathrm{CO}_{2}$. Stained cells were visualized using an LSM700 confocal laser scanning fluorescence microscope equipped with PlanApochromat $63 \mathrm{x} / 1.4$ oil DIC. All images were acquired and processed using ZEN 2012 software. The object-based fluorescence intensity was measured using ImageJ software.

Transmission electron microscopy. A549 and A549/GAK-KO cells were plated $\left(2 \times 10^{5}\right.$ cells/well $)$ in 6 -well plate for $24 \mathrm{~h}$ before treatment and further cultured for $8 \mathrm{~h}$ at $37^{\circ} \mathrm{C}$ with $5 \% \mathrm{CO}_{2}$ under basal-fed (RPMI-1640 supplemented with $10 \%$ FBS), starved condition (RPMI-Gln) or basal-fed with $50 \mu \mathrm{M}$ HCQ conditions. Then, the cells were fixed with $2.5 \%$ glutaraldehyde in $0.1 \mathrm{M}$ phosphate buffer $(\mathrm{pH} 7.3)$ for $1 \mathrm{~h}$ at $4^{\circ} \mathrm{C}$. The samples were further fixed in $1 \%$ osmium tetroxide for $1 \mathrm{~h}$ at $4^{\circ} \mathrm{C}$, dehydrated in a graded ethanol series (30-100\%) and embedded in Quetol 812 epoxy resin (Nisshin EM) for 2 days at $60^{\circ} \mathrm{C}$. Ultrathin sections $(70 \mathrm{~nm})$ were cut using an Ultracut J microtome. The sections were stained with uranium acetate (Merck KGaA) for $15 \mathrm{~min}$ at room temperature in a dark box. After washing with water, the sections were further stained with lead nitrate for $10 \mathrm{~min}$ at room temperature and subjected to electron microscopy using a transmission electron microscope (JEM-1400Flash; JEOL, Ltd.).

Reverse transcription-quantitative PCR ( $q P C R)$. Total RNA was extracted from A549 and A549/GAK-KO cells using the NucleoSpin RNA kit (Takara Bio, Inc.). Total RNA was reverse transcribed into cDNA using the PrimeScript RT Master Mix kit (Takara Bio, Inc.) according to the manufacturer's instructions. Subsequently, qPCR was performed using the SYBR Premix Ex Taq II Tli RNase H Plus kit (Takara Bio, Inc.). The sequences of primers used for qPCR are listed in Table SI. qPCR was performed using a Thermal Cycler Dice Real-Time System TP800 (Takara Bio, Inc.) and the following thermocycling conditions: Initial cDNA denaturation at $95^{\circ} \mathrm{C}$ for 30 sec; followed by 45 cycles of denaturation at $95^{\circ} \mathrm{C}$ for $5 \mathrm{sec}$; and simultaneous annealing and extension at $60^{\circ} \mathrm{C}$ for $30 \mathrm{sec}$. The data were analyzed using Thermal Cycler Dice Real-Time System Software (Takara Bio, Inc.). To determine relative gene expression, the $2^{-\Delta \Delta \mathrm{Cq}}$ method was used (50). mRNA expression levels were normalized to the internal reference gene GAPDH.

Immunoprecipitation. The cDNA of ROCK1 was amplified in the same manner as GAK and cloned into the pcDNA6 vector. The primers used for amplification were as follows: forward, 5'-CACCGCGGCCGCCACCATGTCGACTGG GGACAGTTTTG-3' and reverse, 5'-AGCTGGCGCGCCCGC TAGGTTTGTTTGGGGCAAGC-3'. The expression vectors (4 $\mu \mathrm{g}$ each) for GAK-FLAG and ROCK1-V5 were transfected into $293 \mathrm{~T}$ cells $\left(6 \times 10^{6}\right.$ cells/dish) using Lipofectamine ${ }^{\circledR} 3000$ 
(Invitrogen; Thermo Fisher Scientific, Inc.) and cultured at $37^{\circ} \mathrm{C}$ with $5 \% \mathrm{CO}_{2}$. At $48 \mathrm{~h}$ post-transfection, cells were lysed in $500 \mu \mathrm{l}$ lysis buffer [50 mM Tris- $\mathrm{HCl}(\mathrm{pH} 8.0)$, containing $150 \mathrm{mM} \mathrm{NaCl}$ and $1.0 \% \mathrm{NP}-40$ ] containing a protease inhibitor cocktail. Immunoprecipitation was performed on transfected cell lysates (100 $\mu \mathrm{l}$ each) using anti-FLAG M2 magnetic beads (cat. no. M8823; Sigma-Aldrich; Merck $\mathrm{KGaA} ; 10 \mu \mathrm{l})$. The beads were washed three times with lysis buffer using magnetic separation. Immunoprecipitates were eluted with lysis buffer containing $100 \mu \mathrm{g} / \mathrm{ml} 3$ xFLAG peptide (cat. no. F4799; Sigma-Aldrich; Merck KGaA) and recovered using magnetic separation. Immunoprecipitates or total cell lysates were analyzed by immunoblotting using anti-FLAG $(1: 1,000)$ and anti-V5 $(1: 5,000)$ primary antibodies according to the aforementioned protocol.

Statistical analysis. All data are presented as the mean \pm standard deviation from at least three independent experiments. The unpaired two-tailed Student's t-test or one-way ANOVA followed by Dunnett's or Bonferroni's post hoc test were used to analyze the data using Microsoft Excel version 16.51 (Microsoft Corporation) with the add-in software, Excel Statistical Program File ystat2008 (Igakutosho-shuppan, Ltd.). One-way ANOVA followed by Tukey's post hoc test and two-way ANOVA followed by Bonferroni's post hoc test were used to analyze the data using SPSS version 27 software (IBM Corp.). $\mathrm{P}<0.05$ was considered to indicate a statistically significant difference.

\section{Results}

Targeted disruption of GAK stagnates the autophagic flux and causes LC3B-II accumulation. To analyze the role of GAK in the autophagy-lysosome system, GAK-KO A549-derived cell lines were established (Fig. 1A). GAK was completely knocked out in clones 1-1 and 2-1, but not completely in clone 1-2. The expression of LC3B-II, an autophagosome marker protein, was significantly enhanced in all three clones compared with that in wild-type cells (Fig. 1A and $\mathrm{B}$ ), whereas the expression of LC3B mRNA in GAK-KO cells was similar to that in wild-type cells (Fig. 1C). Therefore, in the following experiments, clone 1-1 was primarily used for the GAK-KO cells, and clones 1-2 and 2-1 were used as needed. The significant enhancement of LC3B-puncta formation in GAK-KO cells compared with that in wild-type cells was detected by immunofluorescence analysis (Fig. 1D-F).

To analyze autophagic flux, a GFP-LC3-mCherryLC $3 \Delta \mathrm{G}$-based system was used $(44,45)$. Briefly, GFP-LC3-mCherry-LC $3 \Delta \mathrm{G}$ is cleaved into equimolar amounts of GFP-LC3 and mCherry-LC3 $\Delta$ G. GFP-LC3 is degraded by autophagy, whereas mCherry-LC $3 \Delta \mathrm{G}$ remains in the cytosol and serves as an internal control. Therefore, autophagic flux can be estimated by calculating the $\mathrm{GFP} / \mathrm{mCherry}$ signal ratio. In the present study, GAK-KO cells showed significantly higher $\mathrm{GFP} / \mathrm{mCherry}$ ratios under basal-fed conditions compared with those in wild-type cells, suggesting that autophagic flux levels were lower in GAK-KO cells compared with those in wild-type cells (Fig. S3A and B). Baf suppressed autophagic flux, as indicated by an increased $\mathrm{GFP} / \mathrm{mCherry}$ ratio, and cytoplasmic accumulation of
GFP-LC3 was more prominent in wild-type cells compared with that in GAK-KO cells (Figs. $1 \mathrm{G}$ and S3C). This result suggested that the additional inhibitory effect of the autophagy inhibitor was decreased in GAK-KO cells because the autophagic flux was already inhibited in the steady-state. By contrast, as indicated by a reduced GFP/mCherry ratio, rapamycin induced autophagic flux, and the elimination rates of GFP-LC3 were more prominent in wild-type cells compared with those in GAK-KO cells (Figs. 1H and S3D). Similarly, starvation conditions (HBSS or RPMI-Gln medium) induced autophagic flux, and the elimination rates of GFP-LC3 were more prominent in wild-type cells compared with those in GAK-KO cells (Figs. 1I, J, S3E and S3F). Collectively, these results suggested that GAK disruption decelerated autophagic flux under basal-fed conditions and reduced the acceleration of autophagic flux under autophagy-inducing conditions, such as starvation.

To analyze the autophagy-related signaling pathways, starvation-refeeding experiments were performed. Both in wild-type and GAK-KO cells, starvation significantly decreased the phosphorylation of mTOR (Ser2448), S6K (Thr389) and S6 (Ser235/236) and induced the phosphorylation of AMPK (Thr172) compared with that in the fed group, indicating that the mTOR signaling pathway was repressed by starvation. Conversely, refeeding significantly induced the phosphorylation of mTOR, S6K and S6 and decreased the phosphorylation of AMPK compared with that in the starved group, indicating that the mTOR signaling pathway was reactivated by refeeding (Fig. S4). Therefore, GAK disruption did not impair starvation and refeeding-induced fluctuations in mTOR signaling. Collectively, these results suggested that the loss of $G A K$ stagnated autophagic flux, but displayed limited effects on the signals that induce autophagosome formation, as well as the formation of autophagosomes.

Impact of GAK disruption on the morphology and function of lysosomes. Transmission electron microscopy (TEM) revealed a notable accumulation of cytoplasmic vesicles in GAK-KO cells (Fig. 2A). To characterize the cytoplasmic vesicles, immunofluorescence analysis was performed. The size distribution of LAMP2-positive vesicles, including lysosomes and autolysosomes, in GAK-KO cells was larger compared with that in wild-type cells (Fig. 2B and C). The protein expression levels of LAMP1 and LAMP2 in GAK-KO cells were significantly higher compared with those in wild-type cells (Fig. S5A and B), whereas the expression levels of LAMP1 and LAMP2 mRNA in GAK-KO cells were similar to those in wild-type cells (Fig. S5C). These data indicated that the de novo synthesis of lysosome-related proteins was not upregulated; however, lysosome-related proteins accumulated in GAK-KO cells under basal-fed conditions. The enlargement of LAMP2-positive vesicles in GAK-KO cells was more prominent under starvation conditions (Fig. 2D-F). Transduction of GAK-KO cells with a GAK-encoding lentivirus canceled the GAK-KO cell-specific phenotype, enlarged LAMP2-positive vesicles (Fig. 2D-F). Additionally, it was shown that the number of LAMP2-positive vesicles in GAK-KO cells was significantly lower compared with that in wild-type cells, and that transduction of GAK-KO cells with a GAK-encoding lentivirus restored the number of LAMP2-positive vesicles (Fig. 2D, E and G). Although 

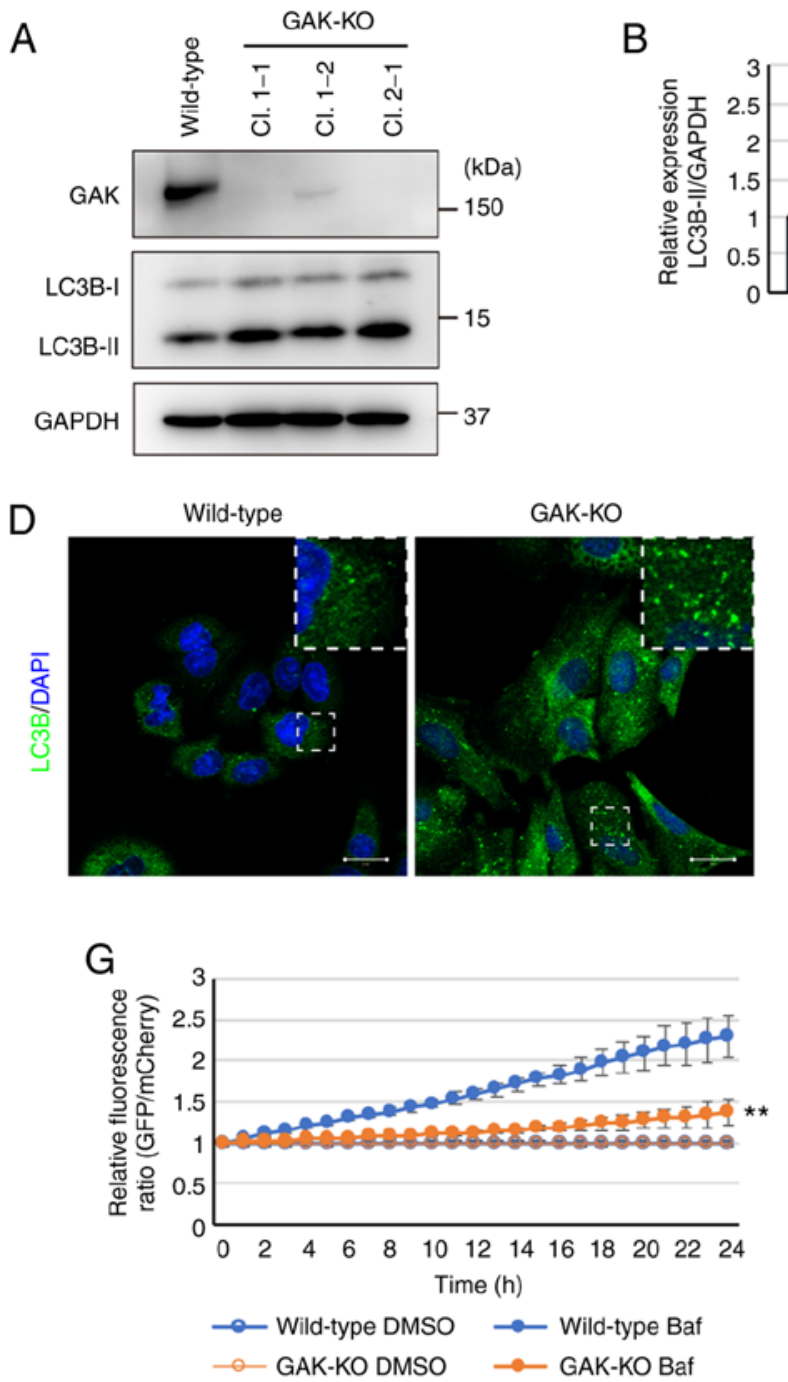

\section{I}

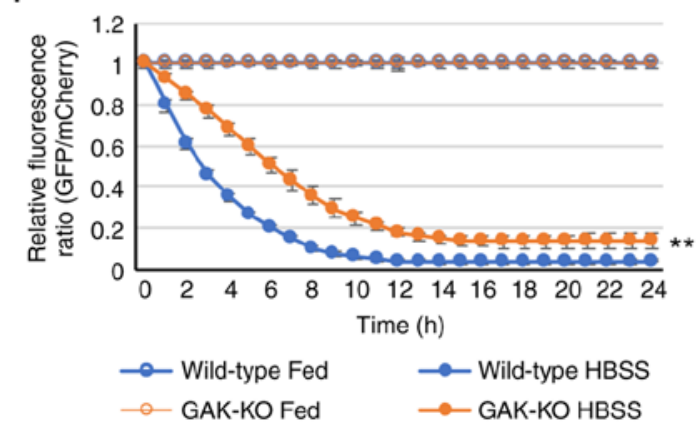

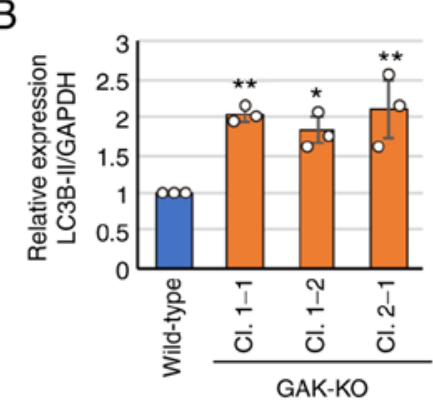

E

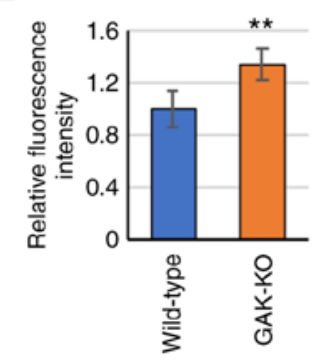

$\mathrm{H}$
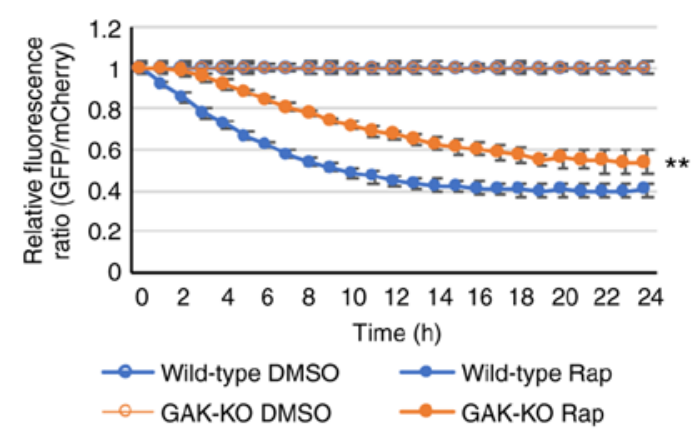

$J$

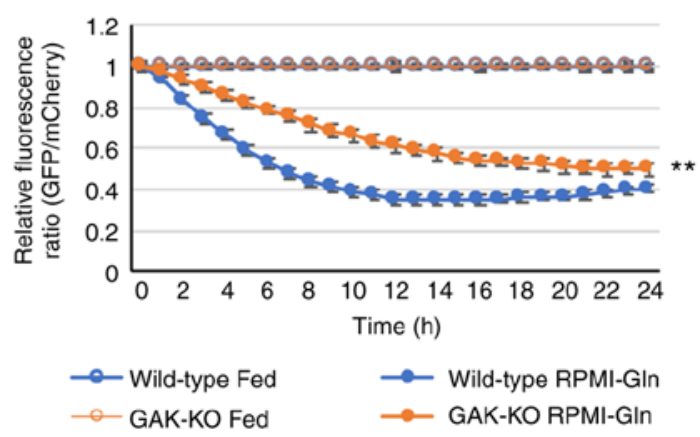

Figure 1. GAK disruption induces LC3B-II accumulation and stagnates autophagic flux. (A) Immunoblot analysis of GAK and LC3B protein expression levels in wild-type and CRISPR/Cas9-mediated GAK-KO (clones 1-1, 1-2 and 2-1) A549 cells. (B) Semi-quantification of relative LC3B-II protein expression levels in wild-type and GAK-KO cells. Data were analyzed using one-way ANOVA followed by Dunnett's post hoc test. Data are presented as the mean \pm SD $(\mathrm{n}=3)$. ${ }^{*} \mathrm{P}<0.05$ and $^{* *} \mathrm{P}<0.01$ vs. wild-type. (C) Reverse transcription-quantitative PCR analysis of relative mRNA expression levels of $L C 3 B$ in wild-type and GAK-KO cells under basal-fed conditions. GAPDH was used as an internal control. Data were analyzed using one-way ANOVA followed by Dunnett's post hoc test. Data are presented as the mean \pm SD $(n=4)$. (D) Immunofluorescence analysis of LC3B (green) in wild-type and GAK-KO cells. The dashed boxed regions are shown at a high magnification (x3) in the inset. Scale bar, $20 \mu \mathrm{m}$. (E) Relative mean fluorescence intensity of LC3B in the cell area. Data were analyzed using an unpaired two-tailed Student's t-test. Data are presented as the mean \pm SD (wild-type $n=52$; GAK-KO, $n=20$ ). **P<0.01 vs. wild-type. (F) Relative number of LC3B puncta per cell area. Data were analyzed using an unpaired two-tailed Student's t-test. Data are presented as the mean \pm SD (wild-type, $n=40$; GAK-KO, $n=25$ ) ${ }^{* *} \mathrm{P}<0.01$ vs. wild-type. (G and H) A549/GFP-LC3-mCherry-LC3 $\Delta$ G and A549/GAK-KO/GFP-LC3-mCherry-LC3 $\Delta$ G cells were treated with (G) $10 \mathrm{nM} \mathrm{Baf}$ or (H) $10 \mathrm{nM}$ rapamycin. The fluorescence intensities derived from GFP-LC3 and mCherry-LC3 $\Delta \mathrm{G}$ were monitored over $24 \mathrm{~h}$. Autophagic flux was determined as alterations in the relative intensities of GFP/mCherry, using DMSO-treated groups as controls. Data were analyzed using two-way ANOVA followed by Bonferroni's post hoc test. Data are presented as the mean $\pm \mathrm{SD}(\mathrm{n}=8){ }^{* * *} \mathrm{P}<0.01$ vs. wild-type. (I and J) A549/GFP-LC3-mCherry-LC3 $\Delta \mathrm{G}$ and A549/GAK-KO/GFP-LC3-mCherry-LC3 $\Delta$ G cells were cultured under starvation conditions using (I) HBSS or (J) RPMI-Gln. The fluorescence intensities derived from GFP-LC3 and mCherry-LC3 $3 \mathrm{G}$ were monitored over $24 \mathrm{~h}$. Autophagic flux was determined as alterations in the relative intensities of GFP/mCherry, using basal-fed condition groups as controls. Data were analyzed using two-way ANOVA followed by Bonferroni's post hoc test. Data are presented as the mean $\pm \mathrm{SD}(\mathrm{n}=8){ }^{* *} \mathrm{P}<0.01$ vs. wild-type. Data are presented as the mean $\pm \mathrm{SD}$. GAK, cyclin G-associated kinase; KO, knockout; Baf, bafilomycin $\mathrm{A}_{1}$; Rap, rapamycin; HBSS, Hanks' balanced salt solution; Gln, glutamine; ns, not significant. 
A
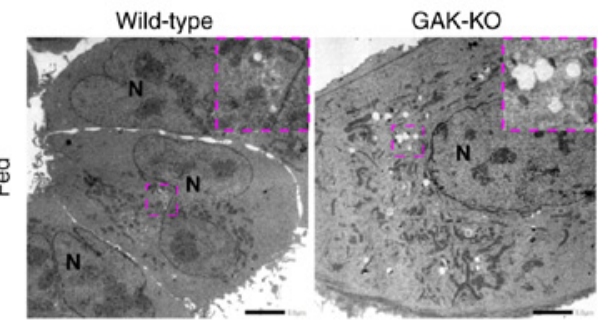

B

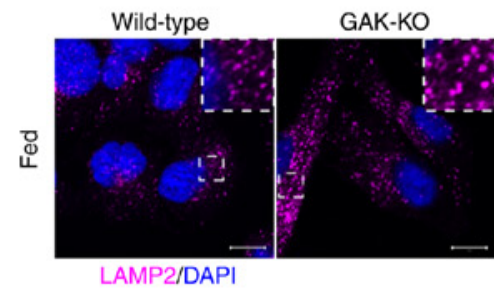

C

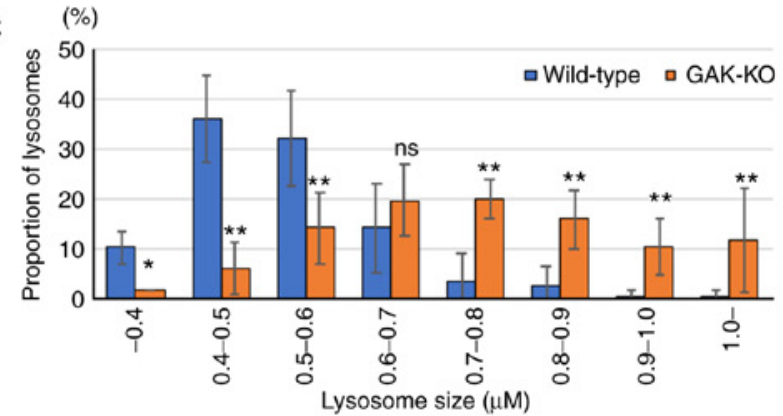

$\mathrm{D}$

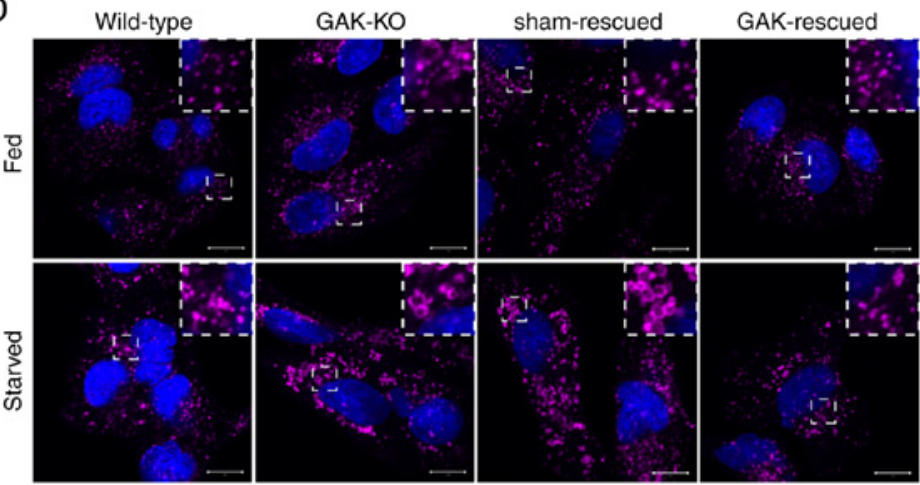

E
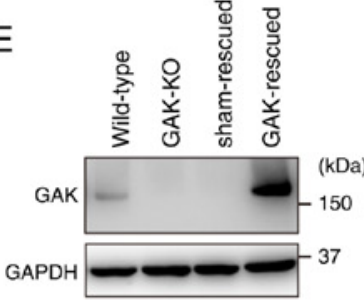

LAMP2/DAPI

$\mathrm{F}$

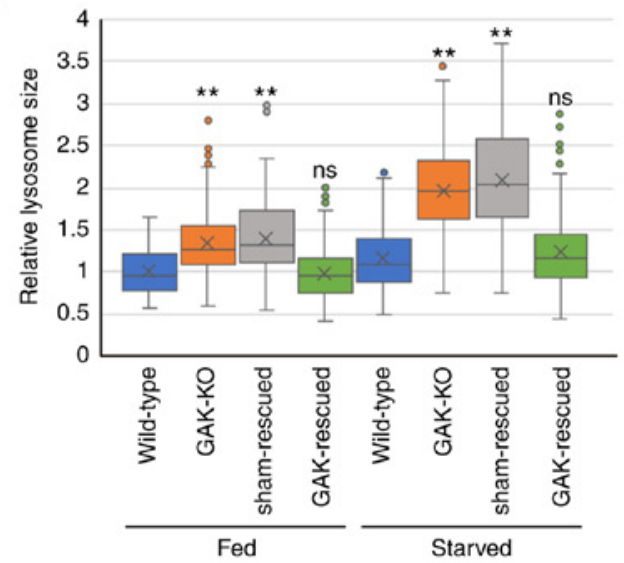

G

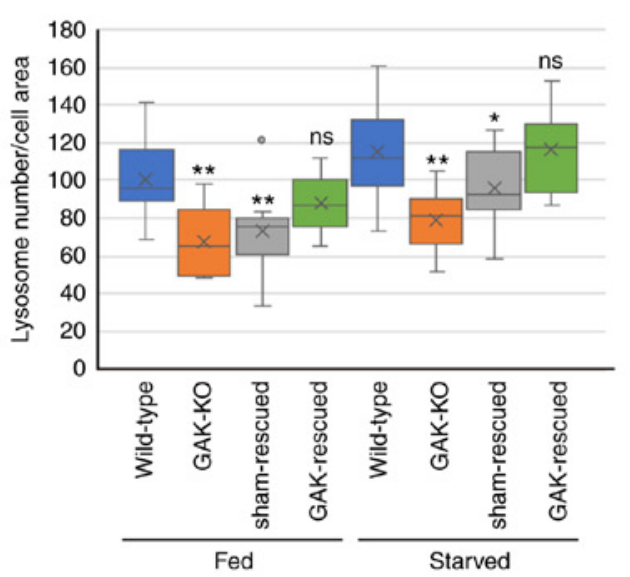

Figure 2. GAK disruption causes the formation of enlarged LAMP2-positive vesicles. (A) Representative transmission electron microscopy images of wild-type and GAK-KO cells under basal-fed conditions. Dashed boxed regions are shown at a high magnification (x3) in the inset. Scale bar, $5 \mu \mathrm{m}$. (B) Immunofluorescence analysis of LAMP2 (magenta) in wild-type and GAK-KO cells under basal-fed conditions. Dashed boxed regions are shown at a high magnification (x3) in the inset. Scale bar, $10 \mu \mathrm{m}$. (C) Lysosomal size in wild-type and GAK-KO cells under basal-fed conditions was quantified using ZEN 2012 software. Data were analyzed using two-way ANOVA followed by Bonferroni's post hoc test. Data are presented as the mean \pm SD (wild-type, n=204; GAK-KO, $\mathrm{n}=295$ ). ${ }^{*} \mathrm{P}<0.05$ and ${ }^{* *} \mathrm{P}<0.01$ vs. wild-type. (D) Immunofluorescence analysis of LAMP2 (magenta) in wild-type, GAK-KO, sham-rescued and GAK-rescued cells under basal-fed or starvation (RPMI-Gln for $8 \mathrm{~h}$ ) conditions. Dashed boxed regions are shown at a high magnification (x3) in the inset. Scale bar, $10 \mu \mathrm{m}$. (E) GAK expression in wild-type, GAK-KO, sham-rescued and GAK-rescued cells was determined by immunoblotting. (F) Lysosomal size in wild-type, GAK-KO, sham-rescued and GAK-rescued cells was quantified using ZEN 2012 software. Data were analyzed using one-way ANOVA followed by Dunnett's post hoc test. The box extends from the lower to the upper quartile, the middle line indicates the median, the $\mathrm{X}$ indicates the mean and the whiskers represent the minimum to maximum values, except for outliers, which are indicated by dots (wild-type/fed, n=212; GAK-KO/fed, n=240; sham-rescued/fed, n=140; GAK-rescued/fed, n=277; wild-type/starved, n=195; GAK-KO/starved, n=112; sham-rescued/starved, n=172; GAK-rescued/starved, $\mathrm{n}=180$ ). ${ }^{* * *} \mathrm{P}<0.01$ vs. wild-type. (G) Number of lysosomes in wild-type, GAK-KO, sham-rescued and GAK-rescued cells was quantified using Imaris. Data were analyzed using one-way ANOVA followed by Dunnett's post hoc test. The box extends from the lower to the upper quartile, the middle line indicates the median, the $\mathrm{X}$ indicates the mean and the whiskers represent the minimum to maximum values, except for outliers, which are indicated by dots (wild-type/fed, $\mathrm{n}=25$; GAK-KO/fed, n=10; sham-rescued/fed, n=9; GAK-rescued/fed, n=12; wild-type/starved, n=21; GAK-KO/starved, n=15; sham-rescued/starved, n=10; GAK-rescued/starved, $\mathrm{n}=16$ ). ${ }^{*} \mathrm{P}<0.05$ and ${ }^{* *} \mathrm{P}<0.01$ vs. wild-type. GAK, cyclin G-associated kinase; KO, knockout; LAMP, lysosomal associated membrane protein; ns, not significant; N, nucleus; Gln, glutamine. 
the expression of lysosome-related genes was not decreased (Fig. S5), the number of lysosomes decreased, suggesting that lysosomal reformation was suppressed in GAK-KO cells.

The enlargement of lysosomes/autolysosomes is accompanied by acidification defects that promote the accumulation of undegradable cargo in these organelles (14). To assess lysosomal function in GAK-KO cells, GAK-KO cells were stained with LysoTracker dye, which is usually trapped in acidified compartments, such as lysosomes. Decreased staining with LysoTracker dye was detected in GAK-KO cells compared with that in wild-type cells under basal-fed conditions, indicating the elevation of lysosomal $\mathrm{pH}$ in GAK-KO cells (Fig. 3A and B). However, under starvation conditions, the intensity of LysoTracker staining in GAK-KO cells was at the same level as that in wild-type cells (Fig. 3A and B). Staining with the LysoSensor dye displayed similar results to the LysoTracker dye (Fig. S6A and B). The maturation rates of CTSB in GAK-KO cells were significantly lower compared with those in wild-type cells under both basal-fed and starvation conditions (Fig. 3C and D). However, mature CTSD expression levels were similar between wild-type and GAK-KO cells (Fig. 3C and D). In addition, the degradation rates of p62/SQSTM1, an autophagy substrate, were also similar between wild-type and GAK-KO cells (Fig. 3E and F). The TEM images revealed a significant accumulation of cytoplasmic vesicles in GAK-KO cells, but the vesicles contained little undigested cargo (Fig. 2A). Collectively, these results indicated that the loss of GAK altered the intra-lysosomal conditions, but essentially maintained the hydrolytic capacity in lysosomes and/or autolysosomes, suggesting that the alteration of intra-lysosomal conditions may not be a major cause of the stagnation of the autophagic flux.

GAK disruption stagnates autophagosome-lysosome fusion and induces the accumulation of autophagosomes and autolysosomes. Subsequently, the formation of autophagosomes and autolysosomes under starvation conditions was assessed. The accumulation of enlarged LC3B-positive puncta was detected in GAK-KO cells at 4-24 h after starvation (Figs. 4A, 4B, S7A and S7B). In addition, enlarged LC3B-positive puncta and enlarged LAMP2-positive vesicles were observed side by side in GAK-KO cells (Fig. 4A). Transduction of GAK-KO cells with a GAK-encoding lentivirus canceled the accumulation of enlarged LC3B-positive puncta and the enlargement of LAMP2-positive vesicles (Fig. 4A and B). In GAK-OE cells, similar to wild-type cells, a small number of enlarged LC3B-positive puncta were detected at $24 \mathrm{~h}$ after starvation, but these were not observed at $10 \mathrm{~h}$ after starvation (Fig. S7C-E). The TEM results verified the accumulation of enlarged autophagosomes and autolysosomes in GAK-KO cells under starvation conditions (Fig. 4C). These observations indicated that the enlarged LAMP2-positive vesicles observed under starvation conditions (Figs. 2D and 4A) were primarily autolysosomes.

Chemical inhibition of GAK kinase activity also induced the accumulation of enlarged LC3B-positive puncta and LAMP2-positive vesicles in a dose-dependent manner under starvation conditions (Fig. 5A-C). GAK-KO cells showed an increase in lysosomal size even under basal-fed conditions (Fig. 2D and F). By contrast, wild-type cells in the presence of the GAKi showed an increase in lysosomal size under starvation conditions, but no increase under basal-fed conditions (Fig. 5A and C), suggesting that the increase in lysosomal size involves more than just the kinase activity of GAK, at least under basal-fed conditions. In addition to A549 cells, H596, PANC-1, and Hep-G2 cells also showed enlarged LC3B-positive puncta in the presence of the GAKi under starvation conditions (Fig. S8). As observed in GAK-KO cells, the GAKi reduced autophagic flux, which was demonstrated by increased elimination rates of GFP-LC3 in a GFP-LC3-mCherry-LC3 $\Delta$ G-based system, in wild-type cells under starvation conditions (Figs. 5D, 5E, S9A and S9B). Wild-type cells in the presence of $30 \mu \mathrm{M}$ GAKi showed a more considerable decrease in autophagic flux compared with that observed in GAK-KO cells (Figs. 1I, 1J, 5D and $5 \mathrm{E}$ ), suggesting that high concentrations of the GAKi may affect proteins other than GAK.

To facilitate the analysis of autophagosome-lysosomal fusion, HCQ, which blocks the late phase of autophagy by increasing the lysosomal $\mathrm{pH}$ (51-53), was used. After $8 \mathrm{~h}$ of treatment with HCQ, most of the LC3B-positive puncta were enclosed within the LAMP2-positive vesicles in wild-type and GAK-rescued cells (Fig. 6A, B and E). By contrast, in GAK-KO cells, most of the LC3B-positive puncta were in contact with the LAMP2-positive vesicles but were not enclosed within them (Fig. 6A, B, and E). However, after $24 \mathrm{~h}$ of treatment with HCQ, most of the LC3B-positive puncta were enclosed within the LAMP2-positive vesicles in GAK-KO and wild-type cells (Fig. 6C-E). After treating GAK-KO cells with HCQ for $8 \mathrm{~h}$, the TEM results also indicated the accumulation of incompletely fused autolysosomes, which presented as snowman-like structures in which spheres were connected (Fig. 6F). Taken together, these results indicated that autophagosome-lysosome fusion was delayed in GAK-KO cells and that GAK kinase activity was required to regulate these steps.

GAK disruption impairs autophagic lysosome reformation. Subsequently, ALR in GAK-KO cells was analyzed. mTOR, which is a key negative regulator of autophagy, is reactivated upon prolonged starvation, triggering ALR (19). Phosphorylation of S6K (Thr389), an indicator of mTOR activity, was reduced by starvation, but induced after $8 \mathrm{~h}$ of starvation in wild-type cells. By contrast, S6K phosphorylation remained decreased even after $8 \mathrm{~h}$ of starvation in GAK-KO cells (Fig. 7A and B). Therefore, mTOR was reactivated in wild-type cells but not in GAK-KO cells.

Prolonged starvation has been reported to induce the formation of reformation tubules from the autolysosomes, which is a characteristic feature of ALR, and the impairment of ALR results in the enlargement of autolysosomes (19,54-56). The accumulation of enlarged LAMP2-positive vesicles in GAK-KO cells under starvation conditions was observed (Figs. 2D, 4A and 7C). Although significant tubule formation, as reported in previous studies $(19,54,56)$, was not confirmed in A549 cells, the deformation of LAMP2-positive vesicles was observed in wild-type and GAK-rescued cells, but not in GAK-KO cells (Fig. 7C and D). These results suggested that ALR was delayed or impaired in GAK-KO cells, which was consistent with the observation that there were fewer LAMP2-positive vesicles in GAK-KO cells compared with in wild-type cells (Fig. 2G). 
A

Wild-type

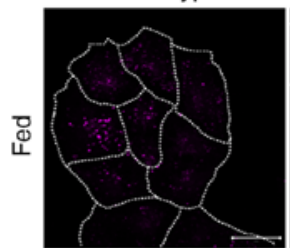

GAK-KO

GAK-rescued

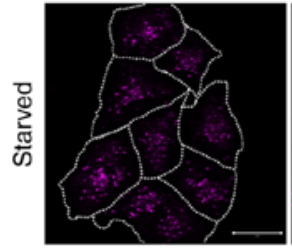

LysoTracker

B

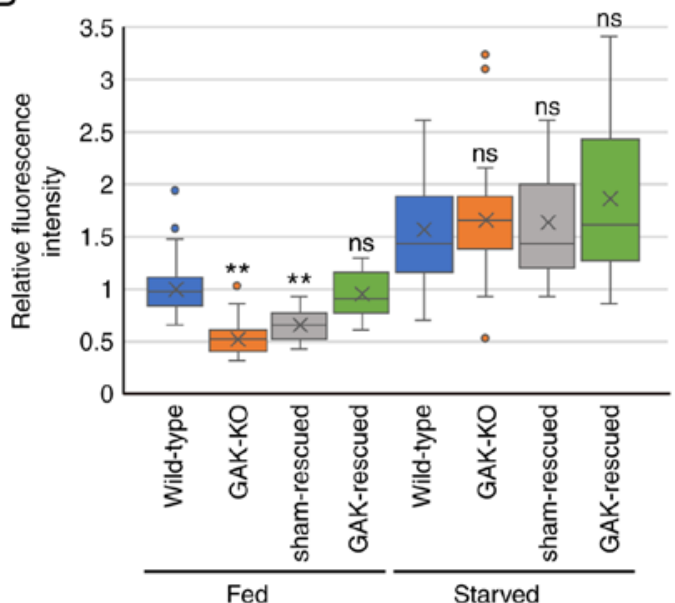

D $\quad$ Wild-type $\because$ GAK-KO

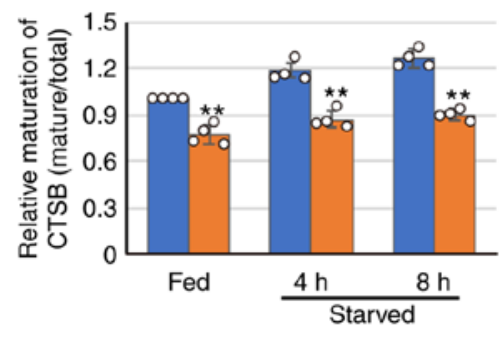

- Wild-type $\square \mathrm{GAK}-\mathrm{KO}$

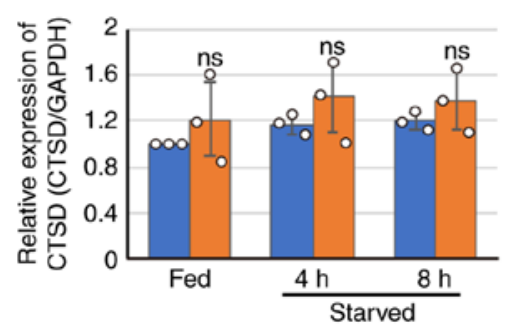

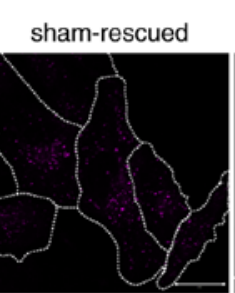
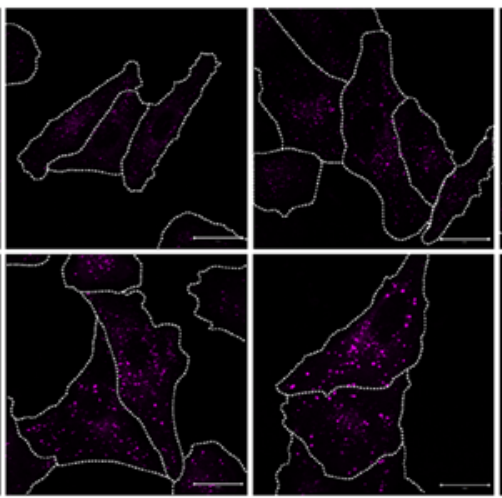

C

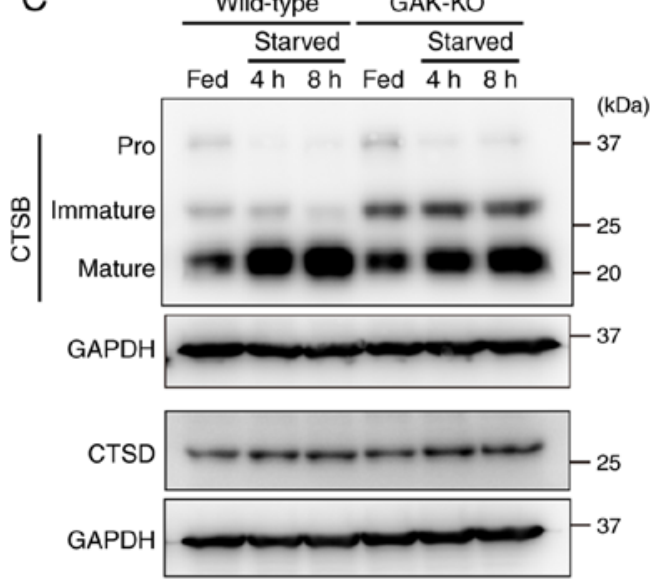

E

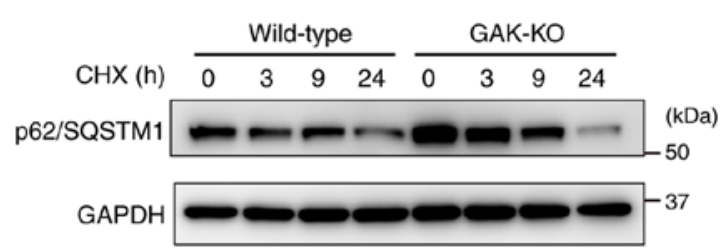

F

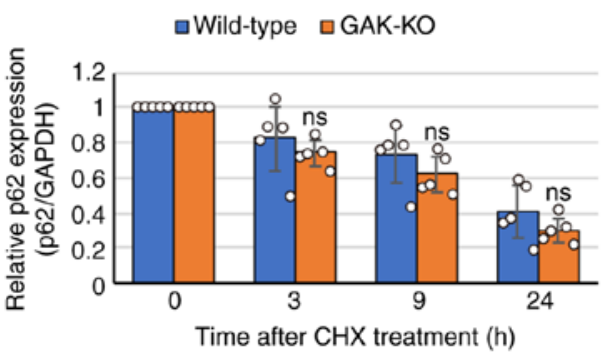

Figure 3. GAK disruption alters the intra-lysosomal conditions. (A) LysoTracker staining in wild-type, GAK-KO, sham-rescued and GAK-rescued cells under basal-fed or starvation conditions (RPMI-Gln for $8 \mathrm{~h}$ ). Scale bar, $20 \mu \mathrm{m}$. (B) Relative mean fluorescence intensities of LysoTracker in wild-type, GAK-KO, sham-rescued and GAK-rescued cells. Data were analyzed using one-way ANOVA followed by Dunnett's post hoc test. The box extends from the lower to the upper quartile, the middle line indicates the median, the $\mathrm{X}$ indicates the mean and the whiskers represent the minimum to maximum values, except for outliers, which are indicated by dots (wild-type/fed, n=63; GAK-KO/fed, n=42; sham-rescued/fed, n=20; GAK-rescued/fed, n=18; wild-type/starved, n=52; GAK-KO/starved, $n=40$; sham-rescued/starved, $n=15$; GAK-rescued/starved, $n=19$ ). ${ }^{* *} \mathrm{P}<0.01$ vs. wild-type. (C) Immunoblot analysis of CTSB and CTSD expression in wild-type and GAK-KO cells under basal-fed or starvation conditions (RPMI-Gln for 4 or 8 h). The membrane for CTSB was stripped and reprobed for GAPDH as the loading control. (D) Semi-quantification of the relative maturation levels of CTSB and relative expression levels of mature CTSD in wild-type and GAK-KO cells. Ratios of mature CTSB/total CTSB and CTSD/GAPDH are presented. Data were analyzed using two-way ANOVA followed by Bonferroni's post hoc test. Data are presented as the mean $\pm \mathrm{SD}(\mathrm{n}=4)$. ${ }^{* *} \mathrm{P}<0.01$ vs. wild-type. (E) Cell lysates were prepared from wild-type and GAK-KO cells after $30 \mu \mathrm{M}$ cycloheximide treatment under basal-fed conditions. The expression of p62/SQSTM1 was analyzed by immunoblotting. (F) Semi-quantification of the relative expression levels of p62 in wild-type and GAK-KO cells. Data were analyzed using two-way ANOVA followed by Bonferroni's post hoc test. Data are presented as the mean \pm SD $(n=5)$. GAK, cyclin G-associated kinase; KO, knockout; CTSD, cathepsin D; Gln, glutamine; CTSB, cathepsin B; SQSTM1, sequestosome 1; CHX, cycloheximide; ns, not significant. 
A
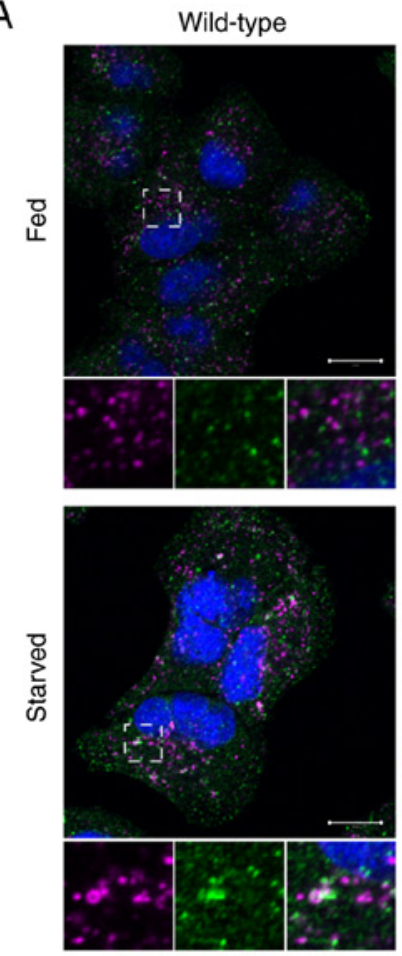

LAMP2/LC3B/DAPI

B

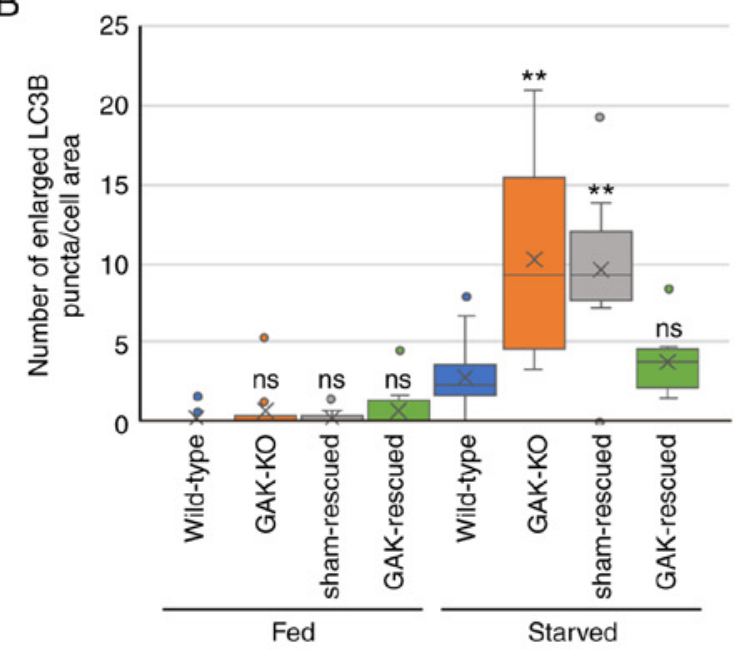

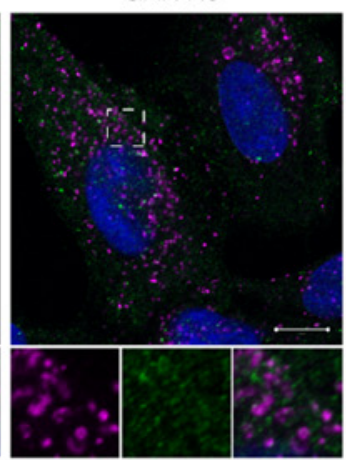

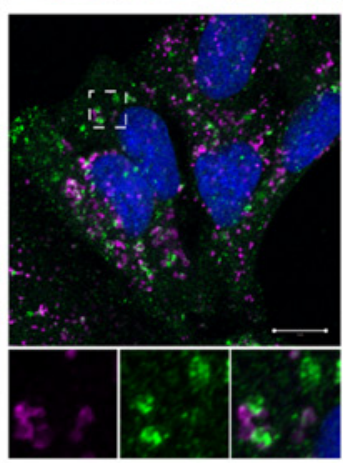

sham-rescued
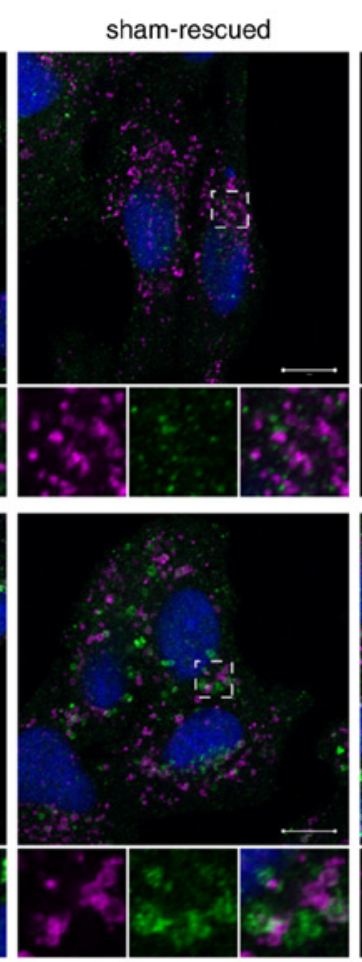

GAK-rescued
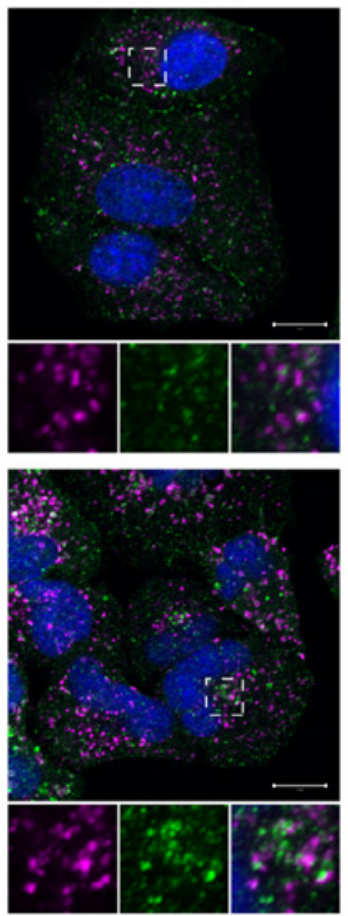

C

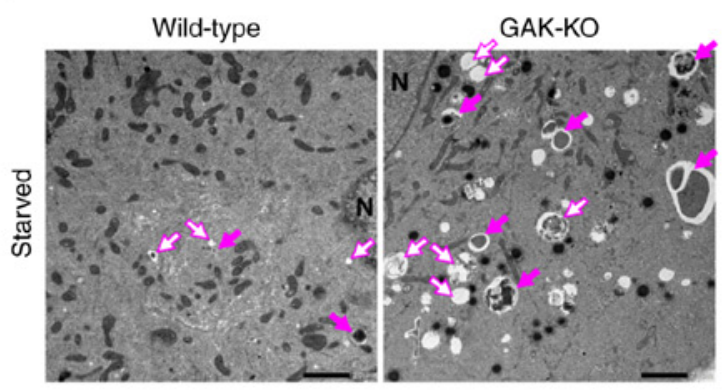

Figure 4. GAK disruption induces the accumulation of autophagosomes and autolysosomes under starvation conditions. (A) Immunofluorescence analysis of LAMP2 (magenta) and LC3B (green) in wild-type, GAK-KO, sham-rescued and GAK-rescued cells under basal-fed or starvation conditions (RPMI-Gln for $8 \mathrm{~h}$ ). The dashed boxed regions are shown at a high magnification (x3) at the bottom. Scale bar, $10 \mu \mathrm{m}$. (B) Number of enlarged LC3B-positive puncta in wild-type, GAK-KO, sham-rescued and GAK-rescued cells was quantified using Imaris. Data were analyzed using one-way ANOVA followed by Dunnett's post hoc test. The box extends from the lower to the upper quartile, the middle line indicates the median, the $\mathrm{X}$ indicates the mean and the whiskers represent the minimum to maximum values, except for outliers, which are indicated by dots (wild-type/fed, n=18; GAK-KO/fed, n=10; sham-rescued/fed, n=9; GAK-rescued/fed, n=11; wild-type/starved, n=18; GAK-KO/starved, n=14; sham-rescued/starved, $n=9 ;$ GAK-rescued/starved, n=10). ${ }^{* *}$ P<0.01 vs. wild-type. (C) Representative transmission electron microscopy images of wild-type and GAK-KO cells under starvation conditions (RPMI-Gln for 8 h). Open arrows indicate autolysosomes and closed arrows indicate autophagosomes. N, nucleus; Scale bar, $2 \mu \mathrm{m}$. GAK, cyclin G-associated kinase; LAMP, lysosomal associated membrane protein; KO, knockout; Gln, glutamine; ns, not significant.

ROCK inhibition mitigates GAK disruption-induced stagnation of autophagic flux. Actin cytoskeleton and myosin motor proteins work together to serve essential roles in each stage of autophagy, such as the formation and transport of vesicular cargoes, the fusion between autophagosomes and lysosomes, and the formation of reformation tubules $(20,21)$. GAK disruption stagnated autophagosome-lysosome fusion and impaired ALR, suggesting the dysregulation of actomyosin in GAK-KO cells. Therefore, the ROCK inhibitor
Y-27632 was used to suppress the function of ROCK (ROCK1 and ROCK2) (57), which mediates actin-myosin contractility and regulates actin cytoskeleton dynamics (58). Treatment with Y-27632 attenuated the accumulation of enlarged LC3B-positive puncta detected in GAK-KO cells under starvation conditions (Figs. 8A, 8B, S10A and S10B). ROCK1 knockdown also attenuated the accumulation of enlarged LC3B-positive puncta detected in GAK-KO cells under starvation conditions (Fig. 9A-C). Furthermore, the 
A
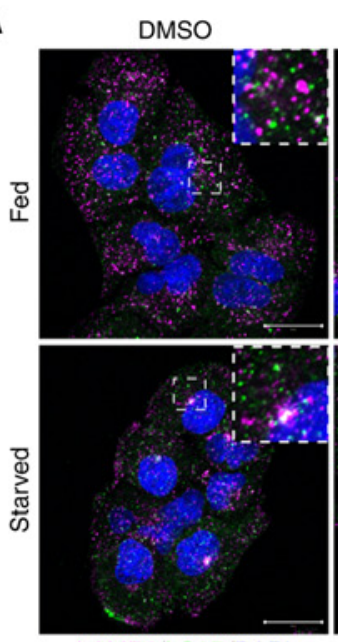

LAMP2/LC3B/DAPI

B

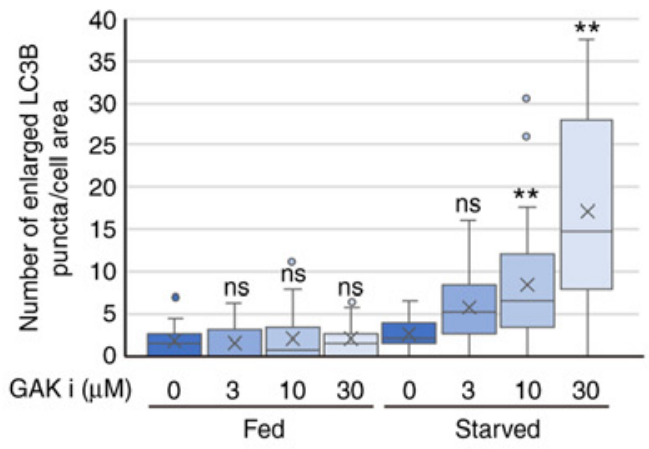

D

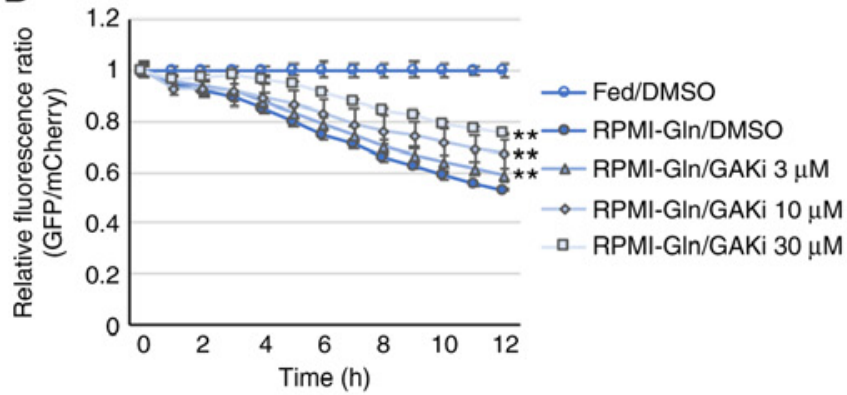

GAKi $10 \mu \mathrm{M}$
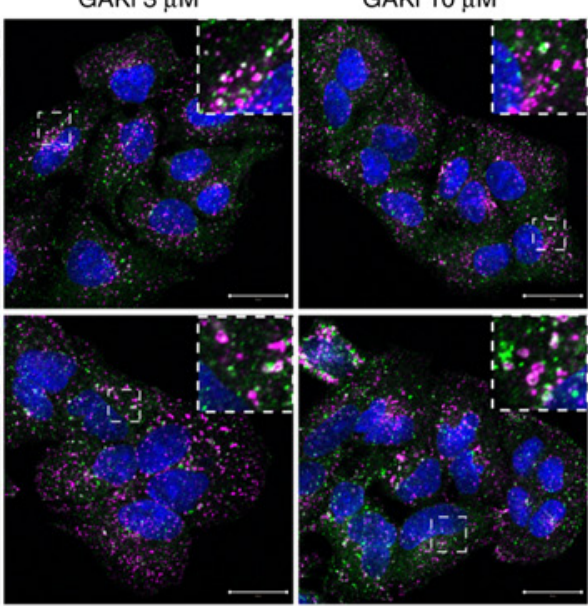

GAKi $30 \mu \mathrm{M}$
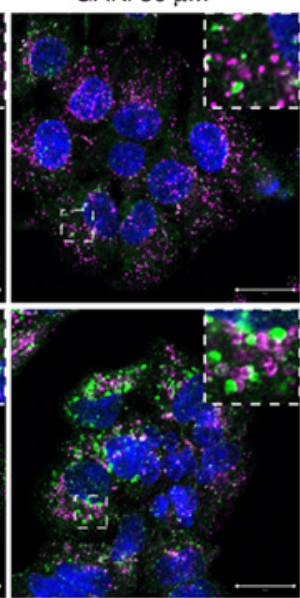

C

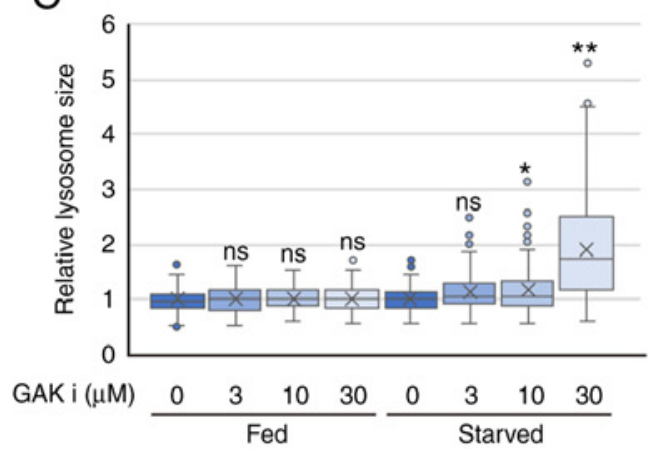

E

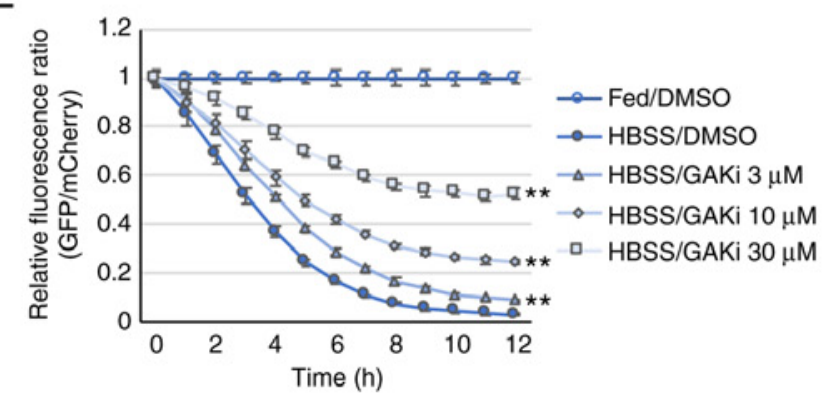

Figure 5. Chemical inhibition of GAK induces the accumulation of autophagosomes and autolysosomes, and stagnates autophagic flux. (A) Immunofluorescence analysis of LAMP2 (magenta) and LC3B (green) in wild-type cells treated with the indicated concentrations of GAKi under basal-fed or starvation conditions (RPMI-Gln for $8 \mathrm{~h}$ ). The dashed boxed regions are shown at a high magnification (x3) in the inset. Scale bar, $20 \mu \mathrm{m}$. (B) Relative number of enlarged LC3B-positive puncta was quantified using Imaris. Data were analyzed using one-way ANOVA followed by Dunnett's post hoc test. The box extends from the lower to the upper quartile, the middle line indicates the median, the $\mathrm{X}$ indicates the mean and the whiskers represent the minimum to maximum values, except for outliers, which are indicated by dots (GAKi $0 \mu \mathrm{M} /$ fed, $\mathrm{n}=29 ; 3 \mu \mathrm{M} / \mathrm{fed}, \mathrm{n}=32 ; 10 \mu \mathrm{M} / \mathrm{fed}, \mathrm{n}=32 ; 30 \mu \mathrm{M} /$ fed, $\mathrm{n}=31 ; 0 \mu \mathrm{M} / \mathrm{starved}, \mathrm{n}=32 ; 3 \mu \mathrm{M} / \mathrm{starved}, \mathrm{n}=27$; $10 \mu \mathrm{M} /$ starved, $\mathrm{n}=35 ; 30 \mu \mathrm{M} /$ starved, $\mathrm{n}=55) .{ }^{* *} \mathrm{P}<0.01$ vs. $0 \mu \mathrm{M}$. (C) Relative lysosomal sizes were quantified using ZEN 2012 software. Data were analyzed using one-way ANOVA followed by Dunnett's post hoc test. The box extends from the lower to the upper quartile, the middle line indicates the median, the $\mathrm{X}$ indicates the mean and the whiskers represent the minimum to maximum values, except for outliers, which are indicated by dots ( $\mathrm{n}=150$ ). ${ }^{*} \mathrm{P}<0.05$ and ${ }^{* *} \mathrm{P}<0.01$ vs. $0 \mu \mathrm{M}$. (D and E) A549/GFP-LC3-mCherry-LC3 $\Delta \mathrm{G}$ cells were treated with the indicated concentrations of GAKi under starvation conditions using (D) RPMI-Gln or (E) HBSS. The fluorescence intensities derived from GFP-LC3 and mCherry-LC3 $\Delta$ G were monitored over 12 h. Autophagic flux was determined as alterations in the relative intensities of GFP/mCherry, using the basal-fed condition group as controls. Data were analyzed using one-way ANOVA followed by Dunnett's post hoc test. Data are presented as the mean \pm SD $(n=8)$. ${ }^{* *} \mathrm{P}<0.01$ vs. RPMI-Gln/DMSO or HBSS/DMSO. GAK, cyclin G-associated kinase; LAMP, lysosomal associated membrane protein; GAKi, GAK inhibitor; Gln, glutamine; HBSS, Hanks' balanced salt solution; ns, not significant.

addition of Baf caused enlargement of the autophagosomes in ROCK1-knockdown GAK-KO cells, which indicated that ROCK1 knockdown in GAK-KO cells restored the fusion between autophagosomes and lysosomes to normal rather than impairing autophagosome formation (Fig. S11). However, no interaction was detected between GAK and ROCK1 (Fig. S12). In addition, treatment with Y-27632
(Fig. 8A and C) or ROCK1 knockdown (Fig. 9B and D) reversed the enlargement of LAMP2-positive vesicles in GAK-KO cells under starvation conditions. Collectively, these results indicated that the disturbance of lysosomal dynamics and the stagnation of autophagic flux due to GAK loss involved a pathway for ROCK-mediated cytoskeletal control (Fig. S13). 
A

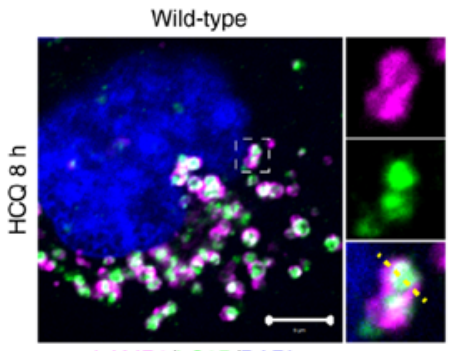

B

LAMP2/LC3B/DAPI

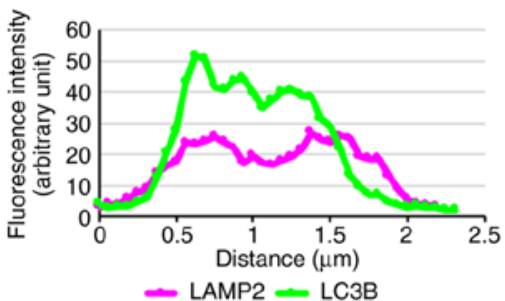

C

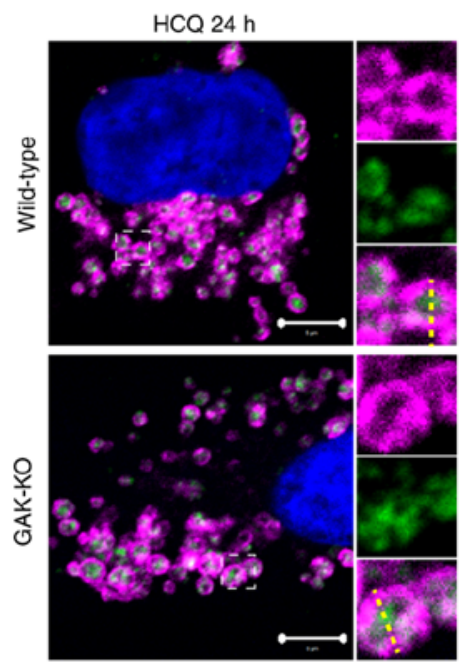

GAK-KO
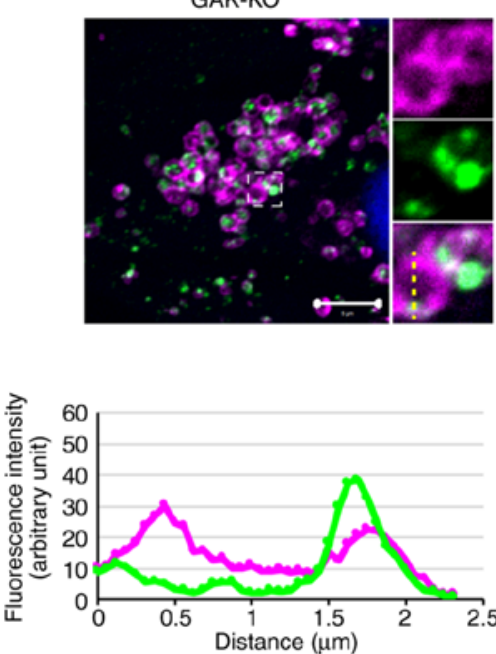

— LAMP2 —LC3B

D

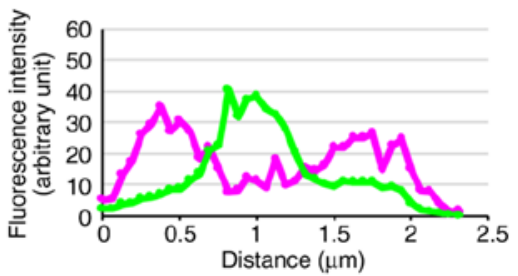

- LAMP2 — LC3B

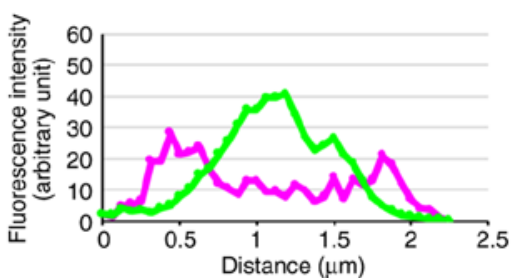

- LAMP2 — LC3B
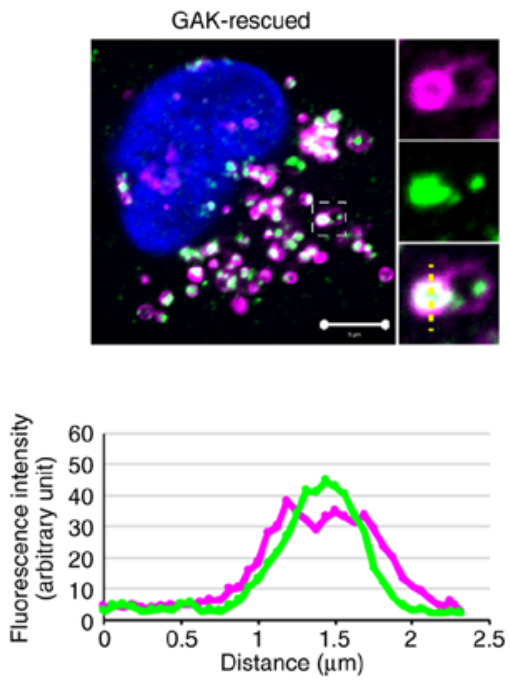

- LAMP2 - LC3B

E
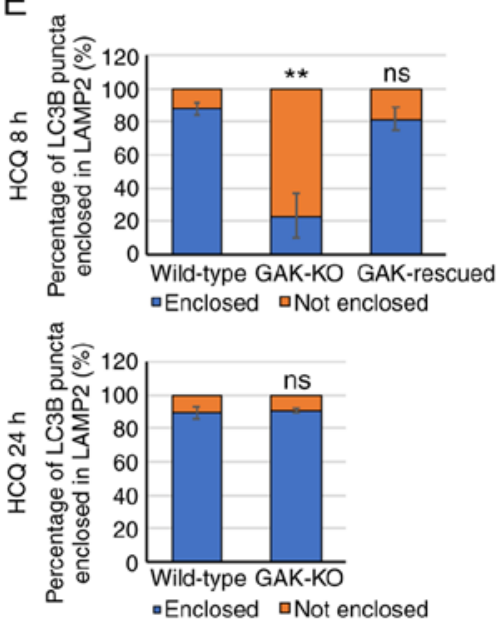

LAMP2/LC3B/DAPI

$\mathrm{F}$

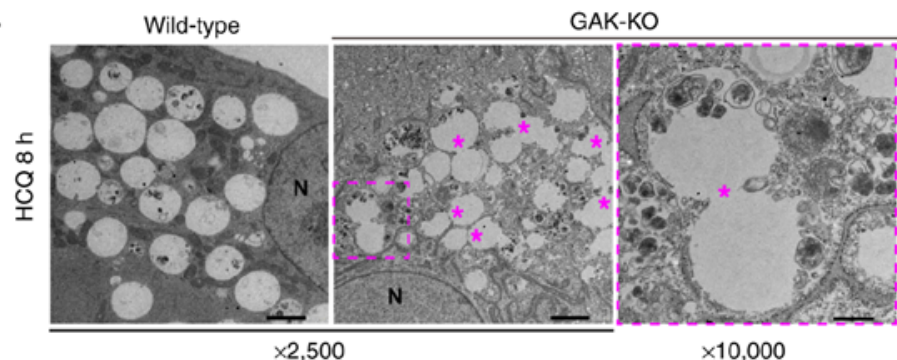

Figure 6. GAK disruption delays autophagosome-lysosome fusion. (A) Immunofluorescence analysis of LAMP2 (magenta) and LC3B (green) in wild-type, GAK-KO and GAK-rescued cells after treatment with $50 \mu \mathrm{M}$ HCQ for $8 \mathrm{~h}$. The dashed boxed regions are shown at a high magnification (x3) on the right. Scale bar, $5 \mu \mathrm{m}$. (B) Intensity profiles of LAMP2 (magenta) and LC3B (green) along the dashed yellow line shown in the magnified image in (A). (C) Immunofluorescence analysis of LAMP2 (magenta) and LC3B (green) in wild-type and GAK-KO cells after treatment with $50 \mu \mathrm{M}$ HCQ for $24 \mathrm{~h}$. The dashed boxed regions are shown at a high magnification (x3) on the right. Scale bar, $5 \mu \mathrm{m}$. (D) Intensity profiles of LAMP2 (magenta) and LC3B (green) along the dashed yellow line shown in the magnified image in (C). (E) Quantification of LC3B-positive puncta enclosed by LAMP2-positive vesicles and those not enclosed. In the upper panel, data were analyzed using one-way ANOVA followed by Dunnett's post hoc test. ${ }^{* *} \mathrm{P}<0.01$ vs. wild-type. In the lower panel, data were analyzed using an unpaired two-tailed Student's t-test. Data are presented as the mean \pm SD (HCQ $8 \mathrm{~h}$; wild-type, n=330; GAK-KO, n=330; GAK-rescued, $\mathrm{n}=316$; and HCQ $24 \mathrm{~h}$; wild-type, $\mathrm{n}=476$; GAK-KO, n=321). (F) Representative transmission electron microscopy images of wild-type and GAK-KO cells after treatment with $50 \mu \mathrm{M}$ HCQ for $8 \mathrm{~h}$. The dashed boxed regions are shown at a high magnification (scale bar, $500 \mathrm{~nm}$ ) on the right. Incompletely fused autolysosomes are indicated by *. Scale bar, $2 \mu \mathrm{m}$. GAK, cyclin G-associated kinase; LAMP, lysosomal associated membrane protein; KO, knockout; HCQ, hydroxychloroquine; ns, not significant.

\section{Discussion}

Lysosomes, which are critical for the terminal degradative stage of autophagy, are highly dynamic organelles that fuse with autophagosomes to form autolysosomes and are reformed from autolysosomes via fission $(9,12)$. The present study demonstrated that GAK may serve an essential role in the autophagy-lysosome system. GAK disruption led to 
A

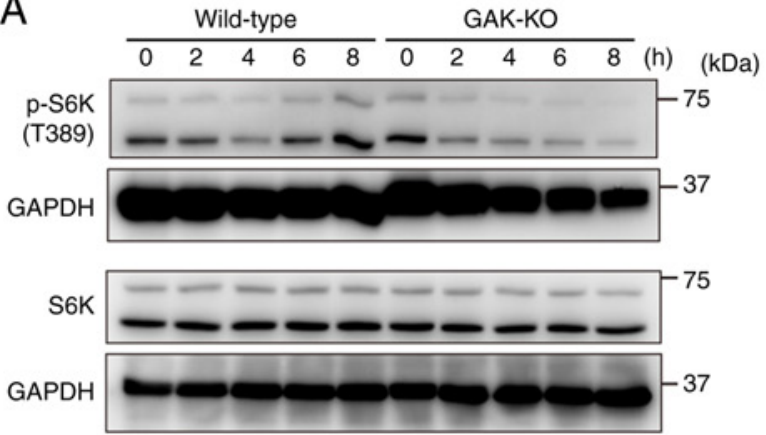

B

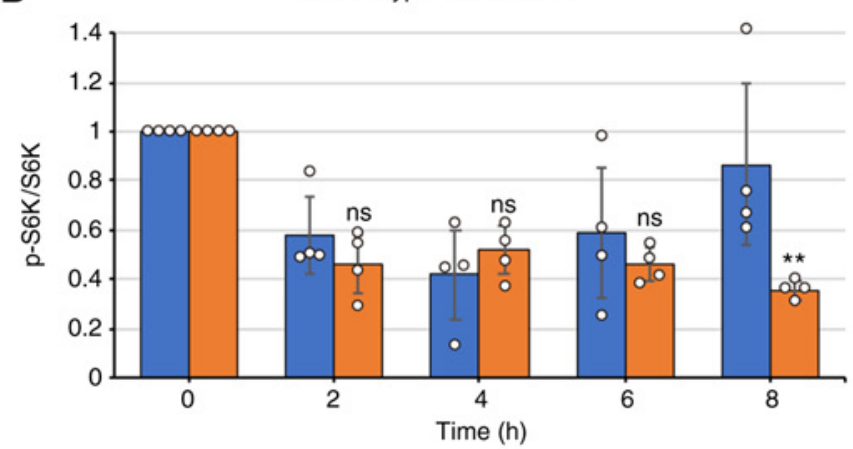

C
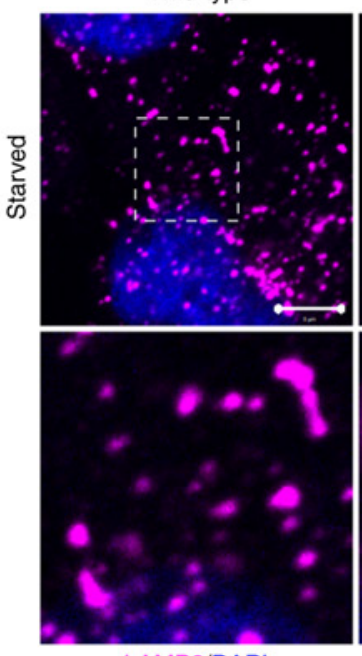

GAK-KO
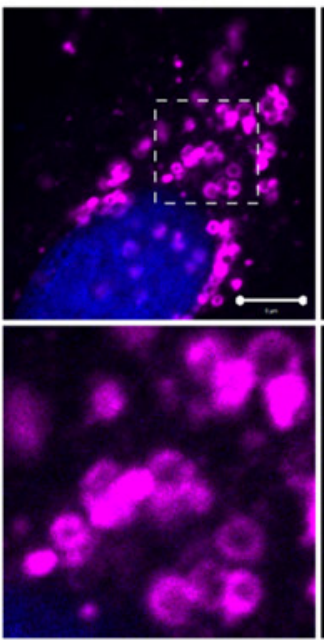

GAK-rescued

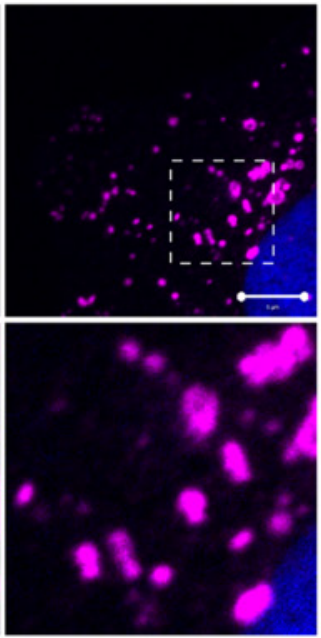

D

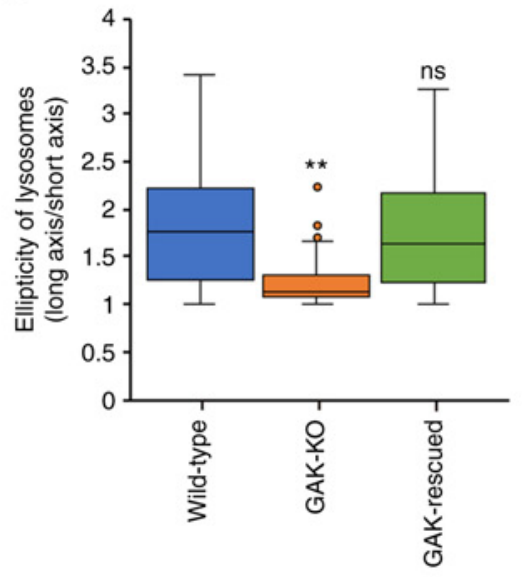

Figure 7. GAK disruption impairs autophagic lysosome reformation. (A) Cell lysates were prepared from wild-type and GAK-KO cells after starvation using RPMI-Gln for the indicated time. Immunoblot analysis of the phosphorylation levels of S6K (Thr389). (B) Densitometry was performed to determine the ratio of p-S6K (Thr389)/total S6K. Data were analyzed using two-way ANOVA followed by Bonferroni's post hoc test. Data are presented as the mean \pm SD ( $\mathrm{n}=4)$. ${ }^{* *} \mathrm{P}<0.01$ vs. wild-type. (C) Immunofluorescence analysis of LAMP2 in wild-type, GAK-KO and GAK-rescued cells under starvation conditions (RPMI-Gln for $8 \mathrm{~h}$ ). The dashed boxed regions are shown at a high magnification (x3) at the bottom. Scale bar, $5 \mu \mathrm{m}$. (D) Long and short axes of lysosomes were measured using ZEN 2012 software and the ratio (long axis/short axis) was calculated. Data were analyzed using one-way ANOVA followed by Dunnett's post hoc test. The box extends from the lower to the upper quartile, the middle line indicates the median, the $\mathrm{X}$ indicates the mean and the whiskers represent the minimum to maximum values, except for outliers, which are indicated by dots $(n=50) .{ }^{* *} \mathrm{P}<0.01$ vs. wild-type. GAK, cyclin G-associated kinase; KO, knockout; Gln, glutamine; S6, ribosomal protein S6; S6K, S6 kinase; p, phosphorylated; LAMP, lysosomal associated membrane protein; ns, not significant.

the stagnation of autophagic flux, accompanied by a marked accumulation of enlarged autolysosomes and autophagosomes under starvation conditions. Moreover, the results indicated that ROCK-mediated actomyosin regulation was involved in the regulation of lysosomal dynamics by GAK.

GAK has been reported to be involved in transporting acid hydrolases, such as CTSD, from the trans-Golgi network to lysosomes via interaction with adaptor protein $1(31,33)$, which is a critical step in the maturation of acid hydrolases and is required to degrade the cargo carried to lysosomes. The present study did not detect immature CTSD in wild-type and GAK-KO A549 cells (data not shown), and there was no marked change in the amount of mature CTSD between wild-type and GAK-KO cells. Regarding CTSB, both mature and immature forms were detected in A549 wild-type cells and GAK-KO cells, and it was shown that GAK disruption suppressed the maturation of CTSB, as previously reported $(31,33)$. Therefore, in addition to the increase in intra-lysosomal $\mathrm{pH}$, suppression of CTSB maturation was observed, and GAK deficiency altered the intra-lysosomal conditions. However, the degradation rates of $\mathrm{p} 62 / \mathrm{SQSTM} 1$ protein, which is degraded by the autophagy-lysosomal pathway, did not change between wild-type cells and GAK-KO cells. Furthermore, no accumulation of undigested content was observed in the enlarged autolysosomes in GAK-KO cells in the TEM images. Therefore, the results suggested that the proteolytic ability of lysosome/autolysosomes was maintained as much as necessary, and alterations to intra-lysosomal conditions are unlikely to be considered as the major cause of the stagnation of autophagic flux.

GAK binds to clathrin and is involved in the control of clathrin-dependent endocytosis $(22,23,29-31)$. Moreover, it has been reported that clathrin is involved in ALR control (54); therefore, GAK may control ALR by binding to clathrin. WASP homolog-associated protein with actin, membranes and microtubules (WHAMM), which serves as a nucleation-promoting factor that stimulates Arp2/3-mediated actin polymerization, is involved in autophagosome biogenesis and ALR (59-61). In addition, the Src substrate cortactin (CTTN), which contributes to the organization of the actin cytoskeleton, is involved in autophagosome-lysosome fusion $(62,63)$. Since the present study demonstrated a relationship between 
A
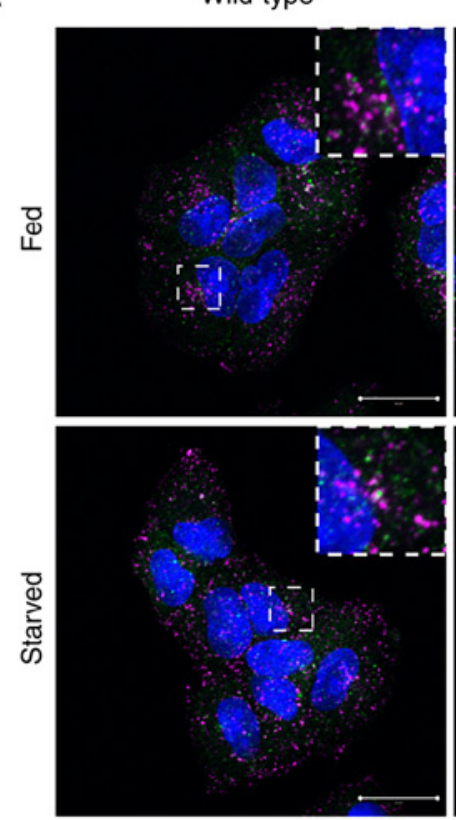

LAMP2/LC3B/DAPI

B

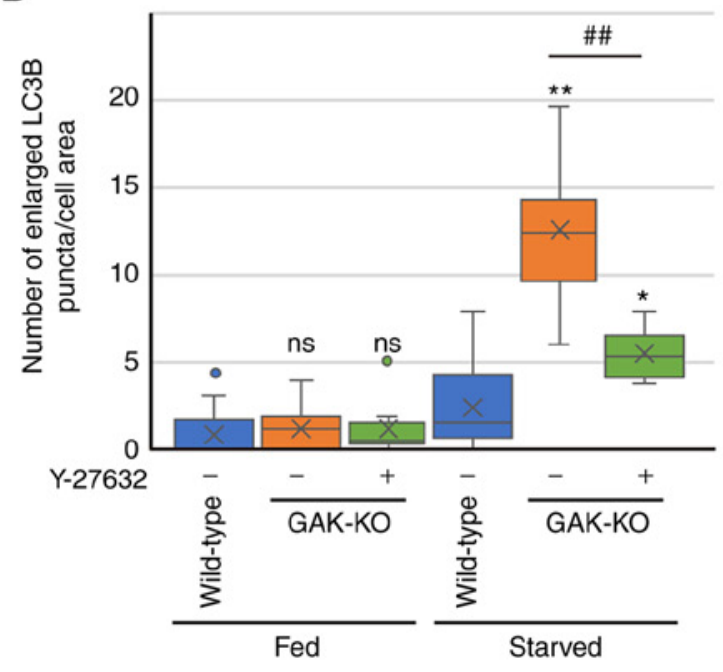

GAK-KO
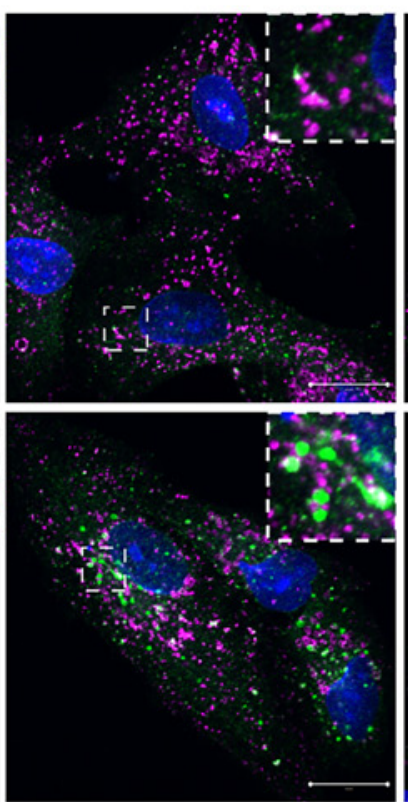

GAK-KO/Y-27632
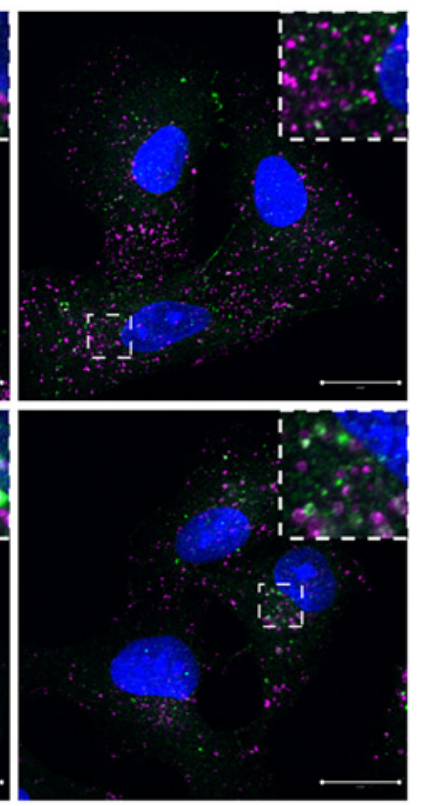

C

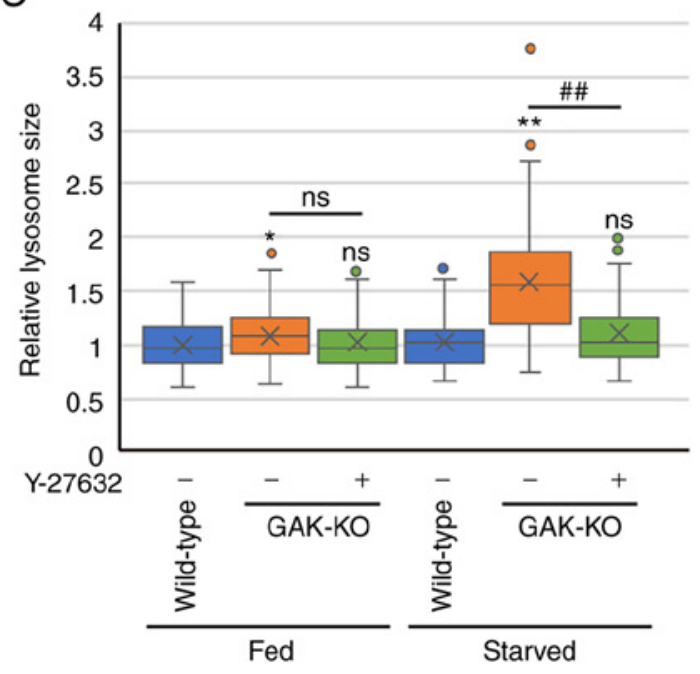

Figure 8. Rho-associated protein kinase inhibition eliminates the accumulation of autophagosomes and autolysosomes induced by GAK disruption. (A) Immunofluorescence analysis of LAMP2 (magenta) and LC3B (green) in wild-type cells, GAK-KO cells and GAK-KO cells treated with Y-27632 under basal-fed or starvation (RPMI-Gln for $8 \mathrm{~h}$ ) conditions. Dashed boxed regions are shown at a high magnification (x3) in the inset. Scale bar, 20 $\mu \mathrm{m}$. (B) Number of enlarged LC3B-positive puncta in wild-type cells, GAK-KO cells and GAK-KO cells treated with Y-27632 was quantified using Imaris. Data were analyzed using one-way ANOVA followed by Tukey's post hoc test. The box extends from the lower to the upper quartile, the middle line indicates the median, the $\mathrm{X}$ indicates the mean and the whiskers represent the minimum to maximum values, except for outliers, which are indicated by dots (wild-type/fed, n=16; GAK-KO/fed, n=10; GAK-KO/Y-27632/fed, n=7; wild-type/starved, n=27; GAK-KO/starved, n=26; GAK-KO/Y-27632/starved, n=25). *P<0.05 and ${ }^{* *} \mathrm{P}<0.01$ vs. wild-type. ${ }^{\# \#} \mathrm{P}<0.01$ vs. GAK-KO. (C) Lysosomal size in wild-type cells, GAK-KO cells and GAK-KO cells treated with Y-27632 quantified using ZEN 2012 software. Data were analyzed using one-way ANOVA followed by Tukey's post hoc test. The box extends from the lower to the upper quartile, the middle line indicates the median, the $\mathrm{X}$ indicates the mean and the whiskers represent the minimum to maximum values, except for outliers, which are indicated by dots $(\mathrm{n}=100)$. ${ }^{*} \mathrm{P}<0.05$ and ${ }^{* *} \mathrm{P}<0.01$ vs. wild-type. ${ }^{\# \#} \mathrm{P}<0.01$ vs. GAK-KO. GAK, cyclin G-associated kinase; LAMP, lysosomal associated membrane protein; KO, knockout; Gln, glutamine; ns, not significant.

GAK and actomyosin regulation, GAK may have a functional interaction with WHAMM and CTTN; however, to the best of our knowledge, there have been no reports so far. It is worth mentioning that yeast actin regulating kinase 1 and p53 regulating kinase 1 , which have homology in the amino acid sequence in the kinase domain with GAK, have been reported to be involved in actin organization and endocytosis (64-66).

GAK has been reported to form a complex indirectly with LRRK2 (34), which has been linked to its role in the autophagy pathway and lysosomal activity in neurons (37). However, the role of GAK in the autophagy pathway has not been elucidated. Mutations in LRRK2 cause inherited PD, and common variants around LRRK2 are risk factors for sporadic PD (67-70). Genome-wide association studies have identified an SNP in GAK as a risk factor for sporadic PD (39-41). The pathophysiology of PD involves mitochondrial dysfunction and oxidative stress $(71,72)$, but increasing evidence suggests that lysosomal dysfunction is also involved (73-75). The 


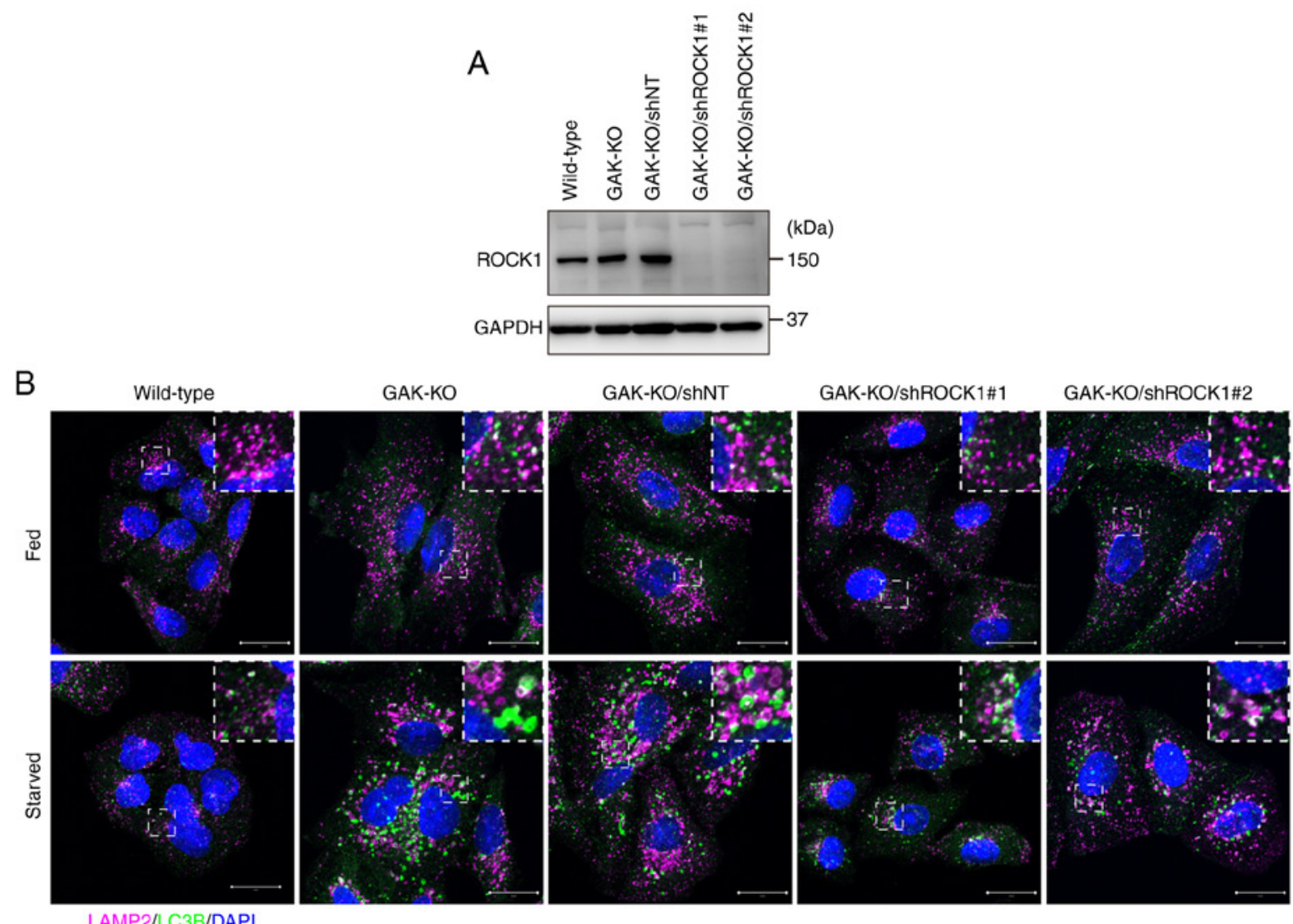

LAMP2/LC3B/DAPI
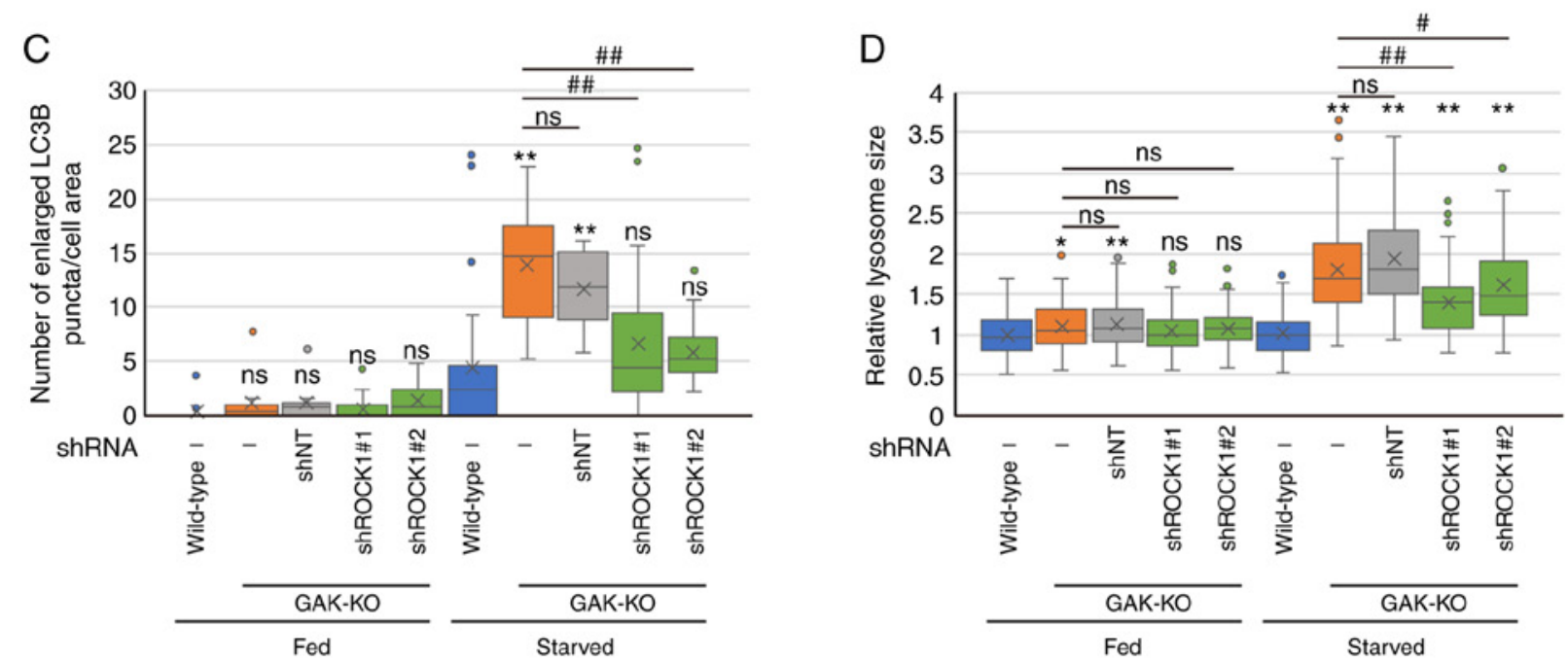

Figure 9. ROCK1 knockdown eliminates the accumulation of autophagosomes and autolysosomes induced by GAK disruption. (A) ROCK1 expression in wild-type, GAK-KO, GAK-KO/shNT and GAK-KO/shROCK1 cells was confirmed by immunoblotting. (B) Immunofluorescence analysis of LAMP2 (magenta) and LC3B (green) in wild-type, GAK-KO, GAK-KO/shNT and GAK-KO/shROCK1 cells under basal-fed or starvation (RPMI-Gln for 8 h) conditions. The dashed boxed regions are shown at a high magnification (x3) in the inset. Scale bar, $20 \mu \mathrm{m}$. (C) Number of enlarged LC3B-positive puncta in wild-type, GAK-KO, GAK-KO/shNT and GAK-KO/shROCK1 cells was quantified using Imaris. Data were analyzed using one-way ANOVA followed by Tukey's post hoc test. The box extends from the lower to the upper quartile, the middle line indicates the median, the $\mathrm{X}$ indicates the mean and the whiskers represent the minimum to maximum values, except for outliers, which are indicated by dots (wild-type/fed, n=16; GAK-KO/fed, n=11; GAK-KO/shNT/fed, n=9; GAK-KO/shROCK1\#1/fed, n=18; GAK-KO/shROCK1\#2/fed, n=22; wild-type/starved, n=27; GAK-KO/starved, n=13; GAK-KO/shNT/starved, n=13; GAK-KO/shROCK1\#1/starved, $\mathrm{n}=28$; GAK-KO/shROCK1\#2/starved, $\mathrm{n}=22$ ). ${ }^{* *} \mathrm{P}<0.01$ vs. wild-type. ${ }^{\# \#} \mathrm{P}<0.01$ vs. GAK-KO. (D) Lysosomal size in wild-type, GAK-KO, GAK-KO/shNT and GAK-KO/shROCK1 cells was quantified using ZEN 2012 software. Data were analyzed using one-way ANOVA followed by Tukey's post hoc test. The box extends from the lower to the upper quartile, the middle line indicates the median, the $\mathrm{X}$ indicates the mean and the whiskers represent the minimum to maximum values, except for outliers, which are indicated by dots $(\mathrm{n}=100)$. ${ }^{*} \mathrm{P}<0.05$ and ${ }^{* *} \mathrm{P}<0.01$ vs. wild-type; ${ }^{*} \mathrm{P}<0.05$ and ${ }^{\# \prime} \mathrm{P}<0.01$ vs. GAK-KO. ROCK, Rho-associated protein kinase; GAK, cyclin G-associated kinase; KO, knockout; sh, short hairpin RNA; NT, non-targeting; LAMP, lysosomal associated membrane protein; Gln, glutamine; ns, not significant.

present study showed that GAK was involved in the regulation of lysosomal dynamics. Therefore, considering the role of LRRK2 shown in previous reports $(34,37,67-70)$, it is possible to speculate that GAK may serve a role in regulating the autophagy-lysosome system in cooperation with LRRK2 and is involved in the development of PD. 
EGFR tyrosine kinase inhibitors (TKIs), such as gefitinib and erlotinib, are used for cancer treatment (76). Previous studies have reported that autophagic flux changes in a cell type- or context-dependent manner when EGFR-TKIs are administered to cancer cells $(44,45,77,78)$. Furthermore, our previous study demonstrated that LC3B-II accumulation after gefitinib administration even in EGFR-KO cells (78). The main target of gefitinib and erlotinib is EGFR, but several molecules, including GAK, have been reported as secondary targets of these drugs $(79,80)$. The present study revealed that GAK inhibition stagnated autophagic flux, which suggested that at least one of the possible causes of the changes in autophagic flux induced by gefitinib administration might be its inhibitory effect on GAK. GAK is overexpressed in various cancer cells, such as osteosarcoma and hormone-refractory prostate cancer cells $(38,81)$. Since autophagy in cancer cells is considered to act in a cytoprotective manner (82-84), gefitinib or erlotinib may be highly effective against cancer cells with high GAK expression.

It is also necessary to consider several additional factors. First, it has been suggested that GAK controls autophagic flux through actomyosin regulation, but the underlying molecular mechanism remains elusive. Autophagy stagnation and accompanying phenomena were observed not only when GAK is knocked out, but also when a GAK kinase inhibitor was applied, suggesting that the kinase activity of GAK might be necessary for this regulation. However, further analysis is needed to identify the GAK substrates involved in regulating the autophagy-lysosome system. Furthermore, it is necessary to clarify the functional relationship between GAK and ROCK in actomyosin regulation. Second, in the present study, only in vitro analyses were performed, and analysis using animal models, such as mice or zebrafish, will be required in the future to confirm these phenomena in vivo. Third, numerous splicing variants have been reported in the GAK (85) and there may be splicing variants that have not yet been identified. In the present study, gRNAs were designed for two different exons of GAK for the production of GAK-KO cells. Similar phenomena were observed in both types of GAK-KO cells. However, these two exons are not commonly used in all splicing variants; therefore, it cannot be completely ruled out that several splicing variants of GAK may remain in each type of GAK-KO cell.

In the present study, GAK, a regulator of clathrin-mediated endocytosis, was found to be involved in the regulation of lysosomal dynamics and autophagic flux. Both endocytosis and autophagy are intracellular membrane vesicle transport systems that are interconnected and influence each other $(86,87)$. Therefore, we propose that GAK may serve as a critical regulator of intracellular membrane traffic and could be a vital coordinator. Further studies on the molecular functions of GAK regarding the regulation of actomyosin should provide important insights into the mechanisms of interconnection and integration of the intracellular membrane vesicle transport system.

\section{Acknowledgements}

The authors would like to thank Dr A. Abe, Mr S. Moriya, Ms A. Hirota and Ms Y. Yamada (Department of Biochemistry, Tokyo Medical University, Japan) for their technical assistance.

\section{Funding}

The present study was supported by the Japan Society for the Promotion of Science KAKENHI (grant no. 18K06901), the MEXT-Supported Program of the Strategic Research Foundation at Private Universities (grant nos. S1411011 and 2014e2018) from the Ministry of Education, Culture, Sports, Science and Technology of Japan and the Tokyo Medical University Research Grant (2020).

\section{Availability of data and materials}

All data generated or analyzed during this study are available from the corresponding author upon reasonable request.

\section{Authors' contributions}

MH, MM and KM designed the study. MM, HKo, JT, MT, $\mathrm{HH}, \mathrm{HKa}, \mathrm{NT}$ and $\mathrm{MH}$ performed the experiments and analyzed the data. MM and $\mathrm{MH}$ confirm the authenticity of all the raw data. MH, MM, NT and KM majorly contributed to drafting the manuscript. All authors read and approved the final manuscript.

\section{Ethics approval and consent to participate}

Not applicable.

\section{Patent consent for publication}

Not applicable.

\section{Competing interests}

The authors declare that they have no competing interests.

\section{References}

1. Morishita $\mathrm{H}$ and Mizushima N: Diverse cellular roles of autophagy. Annu Rev Cell Dev Biol 35: 453-475, 2019.

2. King KE, Losier TT and Russell RC: Regulation of autophagy enzymes by nutrient signaling. Trends Biochem Sci 46: 687-700, 2021.

3. Hara T, Nakamura K, Matsui M, Yamamoto A, Nakahara Y, Suzuki-Migishima R, Yokoyama M, Mishima K, Saito I, Okano H and Mizushima N: Suppression of basal autophagy in neural cells causes neurodegenerative disease in mice. Nature 441: 885-889, 2006.

4. Alers S, Löffler AS, Wesselborg S and Stork B: Role of AMPK-mTOR-Ulk1/2 in the regulation of autophagy: Cross talk, shortcuts, and feedbacks. Mol Cell Biol 32: 2-11, 2012.

5. Galluzzi L,BaehreckeEH,Ballabio A,BoyaP,Bravo-San PedroJM, Cecconi F, Choi AM, Chu CT, Codogno P, Colombo MI, et al: Molecular definitions of autophagy and related processes. EMBO J 36: 1811-1836, 2017.

6. Mercer TJ, Gubas A and Tooze SA: A molecular perspective of mammalian autophagosome biogenesis. J Biol Chem 293: 5386-5395, 2018

7. Nishimura T and Tooze SA: Emerging roles of ATG proteins and membrane lipids in autophagosome formation. Cell Discov 6: 32, 2020.

8. Parzych KR and Klionsky DJ: Vacuolar hydrolysis and efflux: Current knowledge and unanswered questions. Autophagy 15: 212-227, 2019.

9. Yim WW and Mizushima N: Lysosome biology in autophagy. Cell Discov 6: 6, 2020.

10. Kawabata $\mathrm{T}$ and Yoshimori T: Autophagosome biogenesis and human health. Cell Discov 6: 33, 2020. 
11. Mizushima N and Levine B: Autophagy in human diseases. N Engl J Med 383: 1564-1576, 2020.

12. Ballabio A and Bonifacino JS: Lysosomes as dynamic regulators of cell and organismal homeostasis. Nat Rev Mol Cell Biol 21: $101-118,2020$

13. $\mathrm{Pu}$ J, Guardia CM, Keren-Kaplan $\mathrm{T}$ and Bonifacino JS: Mechanisms and functions of lysosome positioning. J Cell Sci 129: 4329-4339, 2016.

14. de Araujo ME, Liebscher G, Hess MW and Huber LA: Lysosomal size matters. Traffic 21: 60-75, 2020.

15. Chen Y and Yu L: Recent progress in autophagic lysosome reformation. Traffic 18: 358-361, 2017.

16. Korolchuk VI, Saiki S, Lichtenberg M, Siddiqi FH, Roberts EA Imarisio S, Jahreiss L, Sarkar S, Futter M, Menzies FM, et al: Lysosomal positioning coordinates cellular nutrient responses. Nat Cell Biol 13: 453-460, 2011

17. Dalle Pezze P, Ruf S, Sonntag AG, Langelaar-Makkinje M, Hall P, Heberle AM, Razquin Navas P, van Eunen K, Tölle RC, Schwarz JJ, et al: A systems study reveals concurrent activation of AMPK and mTOR by amino acids. Nat Commun 7: 13254, 2016.

18. Liu GY and Sabatini DM: mTOR at the nexus of nutrition, growth, ageing and disease. Nat Rev Mol Cell Biol 21: 183-203, 2020.

19. Yu L, McPhee CK, Zheng L, Mardones GA, Rong Y, Peng J, Mi N, Zhao Y, Liu Z, Wan F, et al: Termination of autophagy and reformation of lysosomes regulated by mTOR. Nature 465: 942-946, 2010

20. Kruppa AJ, Kendrick-Jones J and Buss F: Myosins, actin and autophagy. Traffic 17: 878-890, 2016.

21. Kast DJ and Dominguez R: The cytoskeleton-autophagy connec tion. Curr Biol 27: R318-R326, 2017.

22. Greener T, Zhao X, Nojima H, Eisenberg E and Greene LE: Role of cyclin G-associated kinase in uncoating clathrin-coated vesicles from non-neuronal cells. J Biol Chem 275: 1365-1370, 2000

23. Lee DW, Wu X, Eisenberg E and Greene LE: Recruitment dynamics of GAK and auxilin to clathrin-coated pits during endocytosis. J Cell Sci 119: 3502-3512, 2006.

24. Kanaoka Y, Kimura SH, Okazaki I, Ikeda M and Nojima $H$ : GAK: A cyclin G associated kinase contains a tensin/auxilin-like domain. FEBS Lett 402: 73-80, 1997.

25. Shimizu H, Nagamori I, Yabuta $N$ and Nojima H: GAK, a regulator of clathrin-mediated membrane traffic, also controls centrosome integrity and chromosome congression. J Cell Sci 122: 3145-3152, 2009

26. Naito Y, Shimizu H, Kasama T, Sato J, Tabara H, Okamoto A, Yabuta N and Nojima H: Cyclin G-associated kinase regulates protein phosphatase $2 \mathrm{~A}$ by phosphorylation of its $\mathrm{B}^{\prime} \gamma$ subunit. Cell Cycle 11: 604-616, 2012

27. Fukushima K, Wang M, Naito Y, Uchihashi T, Kato Y, Mukai S, Yabuta $\mathrm{N}$ and Nojima H: GAK is phosphorylated by c-Src and translocated from the centrosome to chromatin at the end of telophase. Cell Cycle 16: 415-427, 2017.

28. Yabuno Y, Uchihashi T, Sasakura T, Shimizu H, Naito Y, Fukushima K, Ota K, Kogo M, Nojima H and Yabuta N: Clathrin heavy chain phosphorylated at T606 plays a role in proper cell division. Cell Cycle 18: 1976-1994, 2019.

29. Zhao X, Greener T, Al-Hasani H, Cushman SW, Eisenberg E and Greene LE: Expression of auxilin or AP180 inhibits endocytosis by mislocalizing clathrin: Evidence for formation of nascent pits containing AP1 or AP2 but not clathrin. J Cell Sci 114: 353-365, 2001.

30. Lee DW, Zhao X, Zhang F, Eisenberg E and Greene LE: Depletion of GAK/auxilin 2 inhibits receptor-mediated endocytosis and recruitment of both clathrin and clathrin adaptors. J Cell Sci 118: 4311-4321, 2005

31. Zhang CX, Engqvist-Goldstein AE, Carreno S, Owen DJ, Smythe E and Drubin DG: Multiple roles for cyclin G-associated kinase in clathrin-mediated sorting events. Traffic 6: 1103-1113, 2005.

32. Zhang L, Gjoerup $\mathrm{O}$ and Roberts TM: The serine/threonine kinase cyclin G-associated kinase regulates epidermal growth factor receptor signaling. Proc Natl Acad Sci USA 101: 10296-10301, 2004

33. Kametaka S, Moriyama K, Burgos PV, Eisenberg E, Greene LE, Mattera R and Bonifacino JS: Canonical interaction of cyclin G associated kinase with adaptor protein 1 regulates lysosomal enzyme sorting. Mol Biol Cell 18: 2991-3001, 2007.
34. Beilina A, Rudenko IN, Kaganovich A, Civiero L, Chau H, Kalia SK, Kalia LV, Lobbestael E, Chia R, Ndukwe K, et al: Unbiased screen for interactors of leucine-rich repeat kinase 2 supports a common pathway for sporadic and familial Parkinson disease. Proc Natl Acad Sci USA 111: 2626-2631, 2014.

35. Plowey ED, Cherra SJ III, Liu YJ and Chu CT: Role of autophagy in G2019S-LRRK2-associated neurite shortening in differentiated SH-SY5Y cells. J Neurochem 105: 1048-1056, 2008.

36. Gómez-Suaga P, Luzón-Toro B, Churamani D, Zhang L, Bloor-Young D, Patel S, Woodman PG, Churchill GC and Hilfiker S: Leucine-rich repeat kinase 2 regulates autophagy through a calcium-dependent pathway involving NAADP. Hum Mol Genet 21: 511-525, 2012

37. Madureira M, Connor-Robson N and Wade-Martins R: 'LRRK2: Autophagy and lysosomal activity'. Front Neurosci 14: 498, 2020

38. Susa M, Choy E, Liu X, Schwab J, Hornicek FJ, Mankin H and Duan Z: Cyclin G-associated kinase is necessary for osteosarcoma cell proliferation and receptor trafficking. Mol Cancer Ther 9: 3342-3350, 2010.

39. Rhodes SL, Sinsheimer JS, Bordelon Y, Bronstein JM and Ritz B: Replication of GWAS associations for GAK and MAPT in Parkinson's disease. Ann Hum Genet 75: 195-200, 2011.

40. Dumitriu A, Pacheco CD, Wilk JB, Strathearn KE, Latourelle JC, Goldwurm S, Pezzoli G, Rochet JC, Lindquist S and Myers RH: Cyclin-G-associated kinase modifies $\alpha$-synuclein expression levels and toxicity in Parkinson's disease: Results from the GenePD Study. Hum Mol Genet 20: 1478-1487, 2011.

41. Ma ZG, He F and Xu J: Quantitative assessment of the association between GAK rs $1564282 \mathrm{C} / \mathrm{T}$ polymorphism and the risk of Parkinson's disease. J Clin Neurosci 22: 1077-1080, 2015.

42. Cong L, Ran FA, Cox D, Lin S, Barretto R, Habib N, Hsu PD, Wu X, Jiang W, Marraffini LA and Zhang F: Multiplex genome engineering using CRISPR/Cas systems. Science 339: 819-823, 2013.

43. Ran FA, Hsu PD, Wright J, Agarwala V, Scott DA and Zhang F Genome engineering using the CRISPR-Cas9 system. Nat Protoc 8: 2281-2308, 2013.

44. Tanaka H, Hino H, Moriya S, Kazama H, Miyazaki M, Takano N, Hiramoto M, Tsukahara K and Miyazawa K: Comparison of autophagy inducibility in various tyrosine kinase inhibitors and their enhanced cytotoxicity via inhibition of autophagy in cancer cells in combined treatment with azithromycin. Biochem Biophys Rep 22: 100750, 2020.

45. Kaizuka T, Morishita H, Hama Y, Tsukamoto S, Matsui T, Toyota Y, Kodama A, Ishihara T, Mizushima T and Mizushima N: An autophagic flux probe that releases an internal control. Mol Cell 64: 835-849, 2016.

46. Spangle JM, Ghosh-Choudhury N and Munger K: Activation of cap-dependent translation by mucosal human papillomavirus E6 proteins is dependent on the integrity of the LXXLL binding motif. J Virol 86: 7466-7472, 2012

47. Stewart SA, Dykxhoorn DM, Palliser D, Mizuno H, Yu EY, An DS, Sabatini DM, Chen IS, Hahn WC, Sharp PA, et al: Lentivirus-delivered stable gene silencing by RNAi in primary cells. RNA 9: 493-501, 2003.

48. Yokota A, Hiramoto M, Hino H, Tokuhisa M, Miyazaki M, Kazama H, Takano N and Miyazawa K: Sequestosome 1 (p62) accumulation in breast cancer cells suppresses progesterone receptor expression via argonaute 2. Biochem Biophys Res Commun 531: 256-263, 2020.

49. Lamb CA, Joachim J and Tooze SA: Quantifying autophagic structures in mammalian cells using confocal microscopy. Methods Enzymol 587: 21-42, 2017.

50. Livak KJ and Schmittgen TD: Analysis of relative gene expression data using real-time quantitative PCR and the 2(-Delta Delta C(T)) method. Methods 25: 402-408, 2001.

51. Poole B and Ohkuma S: Effect of weak bases on the intralysosomal $\mathrm{pH}$ in mouse peritoneal macrophages. J Cell Biol 90: 665-669, 1981.

52. Amaravadi RK, Yu D, Lum JJ, Bui T, Christophorou MA, Evan GI, Thomas-Tikhonenko A and Thompson CB: Autophagy inhibition enhances therapy-induced apoptosis in a Myc-induced model of lymphoma. J Clin Invest 117: 326-336, 2007.

53. Maclean KH, Dorsey FC, Cleveland JL and Kastan MB: Targeting lysosomal degradation induces p53-dependent cell death and prevents cancer in mouse models of lymphomagenesis. J Clin Invest 118: 79-88, 2008.

54. Rong Y,Liu M, Ma L, DuW, Zhang H, Tian Y, Cao Z, Li Y, Ren H, Zhang C, et al: Clathrin and phosphatidylinositol-4,5-bisphosphate regulate autophagic lysosome reformation. Nat Cell Biol 14: 924-934, 2012 . 
55. Chang J, Lee $\mathrm{S}$ and Blackstone C: Spastic paraplegia proteins spastizin and spatacsin mediate autophagic lysosome reformation. J Clin Invest 124: 5249-5262, 2014.

56. McGrath MJ, Eramo MJ, Gurung R, Sriratana A, Gehrig SM, Lynch GS, Lourdes SR, Koentgen F, Feeney SJ, Lazarou M, et al: Defective lysosome reformation during autophagy causes skeletal muscle disease. J Clin Invest 131: e135124, 2021.

57. Uehata M, Ishizaki T, Satoh H, Ono T, Kawahara T, Morishita T, Tamakawa H, Yamagami K, Inui J, Maekawa $M$ and Narumiya S: Calcium sensitization of smooth muscle mediated by a Rho-associated protein kinase in hypertension. Nature 389: 990-994, 1997

58. Julian L and Olson MF: Rho-associated coiled-coil containing kinases (ROCK): Structure, regulation, and functions. Small GTPases 5: e29846, 2014

59. Kast DJ, Zajac AL, Holzbaur EL, Ostap EM and Dominguez R: WHAMM Directs the Arp2/3 Complex to the ER for autophagosome biogenesis through an Actin comet tail mechanism. Curr Biol 25: 1791-1797, 2015.

60. Mathiowetz AJ, Baple E, Russo AJ, Coulter AM, Carrano E, Brown JD, Jinks RN, Crosby AH and Campellone KG: An Amish founder mutation disrupts a PI(3)P-WHAMM-Arp2/3 complex-driven autophagosomal remodeling pathway. Mol Biol Cell 28: 2492-2507, 2017

61. Dai A, Yu L and Wang HW: WHAMM initiates autolysosome tubulation by promoting actin polymerization on autolysosomes. Nat Commun 10: 3699, 2019.

62. Nakamura S, Hasegawa J and Yoshimori T: Regulation of lysosomal phosphoinositide balance by INPP5E is essential for autophagosome-lysosome fusion. Autophagy 12: 2500-2501, 2016.

63. Nakamura $\mathrm{S}$ and Yoshimori T: New insights into autophagosome-lysosome fusion. J Cell Sci 130: 1209-1216, 2017.

64. Henry KR, D'Hondt K, Chang JS, Nix DA, Cope MJ, Chan CS, Drubin DG and Lemmon SK: The actin-regulating kinase Prk1p negatively regulates $\mathrm{Scd} 5 \mathrm{p}$, a suppressor of clathrin deficiency, in actin organization and endocytosis. Curr Biol 13: 1564-1569, 2003.

65. Sekiya-Kawasaki M, Groen AC, Cope MJ, Kaksonen M, Watson HA, Zhang C, Shokat KM, Wendland B, McDonald KL, McCaffery JM and Drubin DG: Dynamic phosphoregulation of the cortical actin cytoskeleton and endocytic machinery revealed by real-time chemical genetic analysis. J Cell Biol 162: 765-772, 2003.

66. Toshima J, Toshima JY, Martin AC and Drubin DG: Phosphoregulation of Arp2/3-dependent actin assembly during receptor-mediated endocytosis. Nat Cell Biol 7: 246-254, 2005.

67. Paisán-Ruíz C, Jain S, Evans EW, Gilks WP, Simón J, van der Brug M, López de Munain A, Aparicio S, Gil AM, Khan $\mathrm{N}$, et al: Cloning of the gene containing mutations that cause PARK8-linked Parkinson's disease. Neuron 44: 595-600, 2004.

68. Zimprich A, Biskup S, Leitner P, Lichtner P, Farrer M, Lincoln S, Kachergus J, Hulihan M, Uitti RJ, Calne DB, et al: Mutations in LRRK2 cause autosomal-dominant parkinsonism with pleomorphic pathology. Neuron 44: 601-607, 2004

69. Zimprich A, Müller-Myhsok B, Farrer M, Leitner P, Sharma M, Hulihan M, Lockhart P, Strongosky A, Kachergus J, Calne DB, et al: The PARK8 locus in autosomal dominant parkinsonism: Confirmation of linkage and further delineation of the disease-containing interval. Am J Hum Genet 74: 11-19, 2004.

70. Usmani A, Shavarebi $\mathrm{F}$ and Hiniker A: The Cell Biology of LRRK2 in Parkinson's disease. Mol Cell Biol 41: e00660-20, 2021.

71. Clark EH, Vázquez de la Torre A, Hoshikawa T and Briston T: Targeting mitophagy in Parkinson's disease. J Biol Chem 296: $100209,2020$.
72. Malpartida AB, Williamson M, Narendra DP, Wade-Martins R and Ryan BJ: Mitochondrial dysfunction and mitophagy in Parkinson's disease: From mechanism to therapy. Trends Biochem Sci 46: 329-343, 2020.

73. Plotegher N and Duchen MR: Crosstalk between Lysosomes and Mitochondria in Parkinson's disease. Front Cell Dev Biol 5: 110, 2017.

74. Nguyen M, Wong YC, Ysselstein D, Severino A and Krainc D: Synaptic, Mitochondrial, and Lysosomal dysfunction in Parkinson's disease. Trends Neurosci 42: 140-149, 2019.

75. Vidyadhara DJ, Lee JE and Chandra SS: Role of the endolysosomal system in Parkinson's disease. J Neurochem 150: 487-506, 2019.

76. Oxnard GR, Janjigian YY, Arcila ME, Sima CS, Kass SL, Riely GJ, Pao W, Kris MG, Ladanyi M, Azzoli CG and Miller VA: Maintained sensitivity to EGFR tyrosine kinase inhibitors in EGFR-mutant lung cancer recurring after adjuvant erlotinib or gefitinib. Clin Cancer Res 17: 6322-6328, 2011.

77. Han W, Pan H, Chen Y, Sun J, Wang Y, Li J, Ge W, Feng L, Lin X, Wang X, et al: EGFR tyrosine kinase inhibitors activate autophagy as a cytoprotective response in human lung cancer cells. PLoS One 6: e18691, 2011.

78. Sugita S, Ito K, Yamashiro Y, Moriya S, Che XF, Yokoyama T, Hiramoto $M$ and Miyazawa K: EGFR-independent autophagy induction with gefitinib and enhancement of its cytotoxic effect by targeting autophagy with clarithromycin in non-small cell lung cancer cells. Biochem Biophys Res Commun 461: 28-34, 2015.

79. Brehmer D, Greff Z, Godl K, Blencke S, Kurtenbach A, Weber M, Müller S, Klebl B, Cotton M, Kéri G, et al: Cellular targets of gefitinib. Cancer Res 65: 379-382, 2005.

80. Yamamoto N, Honma M and Suzuki H: Off-target serine/threonine kinase 10 inhibition by erlotinib enhances lymphocytic activity leading to severe skin disorders. Mol Pharmacol 80: 466-475, 2011

81. Ray MR, Wafa LA, Cheng H, Snoek R, Fazli L, Gleave M and Rennie PS: Cyclin G-associated kinase: A novel androgen receptor-interacting transcriptional coactivator that is overexpressed in hormone refractory prostate cancer. Int J Cancer 118: 1108-1119, 2006

82. Sooro MA, Zhang N and Zhang P: Targeting EGFR-mediated autophagy as a potential strategy for cancer therapy. Int J Cancer 143: 2116-2125, 2018.

83. Wu M and Zhang P: EGFR-mediated autophagy in tumourigenesis and therapeutic resistance. Cancer Lett 469: 207-216, 2020.

84. Rehman SK, Haynes J, Collignon E, Brown KR, Wang Y, Nixon AM, Bruce JP, Wintersinger JA, Singh Mer A, Lo EB, et al: Colorectal cancer cells enter a Diapause-like DTP state to survive chemotherapy. Cell 184: 226-242.e221, 2021.

85. Nagle MW, Latourelle JC, Labadorf A, Dumitriu A, Hadzi TC Beach TG and Myers RH: The 4p16.3 Parkinson disease risk locus is associated with GAK expression and genes involved with the synaptic vesicle membrane. PLoS One 11: e0160925, 2016.

86. Tumbarello DA, Kendrick-Jones J and Buss F: Myosin VI and its cargo adaptors-linking endocytosis and autophagy. J Cell Sci 126: 2561-2570, 2013.

87. Bilanges B, Posor Y and Vanhaesebroeck B: PI3K isoforms in cell signalling and vesicle trafficking. Nat Rev Mol Cell Biol 20: 515-534, 2019.

This work is licensed under a Creative Commons Attribution-NonCommercial-NoDerivatives 4.0 International (CC BY-NC-ND 4.0) License. 